\title{
Switching from astrocytic neuroprotection to neurodegeneration by cytokine stimulation
}

\author{
Liudmila Efremova $^{1,2} \cdot$ Petra Chovancova $^{1,3} \cdot$ Martina Adam $^{1} \cdot$ Simon Gutbier ${ }^{1,2}$. \\ Stefan Schildknecht ${ }^{1} \cdot$ Marcel Leist $^{1}$
}

\begin{abstract}
Astrocytes, the largest cell population in the human brain, are powerful inflammatory effectors. Several studies have examined the interaction of activated astrocytes with neurons, but little is known yet about human neurotoxicity under such situations and about strategies of neuronal rescue. To address this question, immortalized murine astrocytes (IMA) were combined with human LUHMES neurons and stimulated with an inflammatory (TNF, IL-1) cytokine mix (CM). Neurotoxicity was studied both in co-cultures and in monocultures after transfer of conditioned medium from activated IMA. Interventions with $>20$ drugs were used to profile the model system. Control IMA supported neurons and protected them from neurotoxicants. Inflammatory activation reduced this protection, and prolonged exposure of co-cultures to $\mathrm{CM}$ triggered neurotoxicity. Neither the added cytokines nor the release of NO from astrocytes
\end{abstract}

Liudmila Efremova and Petra Chovancova have contributed equally to this study. were involved in this neurodegeneration. The neurotoxicity-mediating effect of IMA was faithfully reproduced by human astrocytes. Moreover, glia-dependent toxicity was also observed, when IMA cultures were stimulated with $\mathrm{CM}$, and the culture medium was transferred to neurons. Such neurotoxicity was prevented when astrocytes were treated by p38 kinase inhibitors or dexamethasone, whereas such compounds had no effect when added to neurons. Conversely, treatment of neurons with five different drugs, including resveratrol and CEP1347, prevented toxicity of astrocyte supernatants. Thus, the sequential IMA-LUHMES neuroinflammation model is suitable for separate profiling of both glial-directed and directly neuroprotective strategies. Moreover, direct evaluation in co-cultures of the same cells allows for testing of therapeutic effectiveness in more complex settings, in which astrocytes affect pharmacological properties of neurons.

Keywords LUHMES - Astrocyte · p38 kinase · Neuroinflammation $\cdot$ Neuropharmacology

1 Doerenkamp-Zbinden Chair for In Vitro Toxicology and Biomedicine, University of Konstanz, PO Box M657, 78457 Constance, Germany

2 Research Training Group 1331 (RTG1331), University of Konstanz, Constance, Germany

3 Konstanz Research School Chemical Biology, University of Konstanz, Constance, Germany 


$\begin{array}{ll}\text { Abbreviations } \\ \text { PD } & \text { Parkinson's disease } \\ \text { DA } & \text { Dopaminergic } \\ \text { MPP } & \text { 1-Methyl-4-phenyl-pyridinium } \\ \text { PARP } & \text { Poly-(ADP-ribose)-polymerase } \\ \text { PLO } & \text { Poly-L-ornithine } \\ \text { GDNF } & \text { Glial-derived neurotrophic factor } \\ \text { IMA } & \text { Immortalized mouse astrocytes } \\ \text { LDH } & \text { Lactate dehydrogenase } \\ \text { DTNB } & \text { 5,5'-Dithiobis(2-nitrobenzoic acid) } \\ \text { GSH } & \text { Glutathione } \\ \text { GSSG } & \text { L-Glutathione oxidized } \\ \text { DHQ } & \text { 1,5-Isoquinolinediol } \\ \text { CEP1347 } & \text { (3,9-Bis[(ethylthio)methyl]-K-252a) } \\ \text { ROCK } & \text { Rho kinase } \\ \text { DM } & \text { Differentiation medium } \\ \text { DAT } & \text { Dopamine transporter } \\ \text { LUHMES } & \text { Lund human mesencephalic cells } \\ \text { TNF- } \alpha & \text { Tumor necrosis factor alpha } \\ \text { IL-1 } \beta & \text { Interleukin-1 beta } \\ \text { IFN- } \gamma & \text { Interferon gamma } \\ \text { CM } & \text { Cytokine mix } \\ \text { CCM } & \text { Complete cytokine mix } \\ \text { L-NNA } & \text { N } \omega \text {-nitro-L-arginine } \\ \text { CNS } & \text { Central nerve system } \\ \text { VMAT2 } & \text { Vesicular monoamine transporter } \\ \text { TH } & \text { Tyrosine hydroxylase } \\ \text { NHA } & \text { Normal human astrocytes } \\ \text { NF-kB } & \text { Nuclear factor kappa-light-chain-enhancer of } \\ & \text { activated B cells } \\ \text { IkB } & \text { NF-kappa-B inhibitor beta } \\ \text { COX2 } & \text { Cyclooxygenase-2 } \\ \text { NOS } & \text { Nitric oxide synthase } \\ \text { cAMP } & \text { Cyclic adenosine monophosphate } \\ \text { NEP } & \text { Neuroepithelial cells } \\ \text { mAGES } & \text { Mouse astrocytes generated from embryonic } \\ \text { SNpc } & \text { stem cells } \\ \text { LPS } & \text { Substantia nigra pars compacta } \\ \text { NSE } & \text { Neuron-specific enolase } \\ & \end{array}$

\section{Introduction}

Inflammatory situations and several inflammation-related mediators can trigger or aggravate neuronal damage in experimental models (Hashioka et al. 2015; Hunter et al. 2009). They may also be involved in several neurodegenerative diseases, and modulation of inflammation may contribute to current and future treatments (Gao et al. 2011; Heneka et al. 2014, 2015; In'T Veld et al. 2001; Rees et al. 2011; Ruitenberg et al. 2001). At present, only few drugs are available that reach therapeutically effective levels within the brain and can be tolerated well for prolonged treatment periods. Moreover, most drugs have been developed for other indications, and the inflammatory key players and processes in the brain differ strongly from betterexamined situations in the body periphery. Specific target cells in the central nervous system include microglia, a cell type related to peripheral macrophages but of distinctly different developmental origin (Gomez Perdiguero et al. 2015), and astrocytes, an often neglected cell population that has a moderate abundance in rodent brains, but exceeds the number of neurons in human brain by threefold to tenfold (Cahoy et al. 2008; Volterra and Meldolesi 2005). Astrocytes have a peculiar double function, as major neurosupportive cell population in the healthy brain, and as powerful inflammatory cells that may exert detrimental effects in disease situations (Allen and Barres 2009; Maragakis and Rothstein 2006; Orre et al. 2014; Sofroniew and Vinters 2010).

Besides a general maintenance of brain homeostasis, astrocytes can protect neurons in multiple ways. For instance, they secrete neurotrophins such as GDNF or CDNF (Lindholm et al. 2007), supply antioxidants and other beneficial factors (Cipriani et al. 2012; Pizzurro et al. 2014; Shih et al. 2003), promote synaptogenesis (Dodla et al. 2010), foster neuritogenesis (Guizzetti et al. 2008), and allow growth under unfavorable conditions (Kuegler et al. 2012).

There is genetic evidence that astrocytes can contribute to neuropathology, e.g., in the RETT syndrome (Lioy et al. 2011; Williams et al. 2014), amyotrophic lateral sclerosis (ALS) (Nagai et al. 2007), or Huntington's disease (Valenza et al. 2015). However, for most other situations, the role of these cells, as bystander or aggressor, is less understood. It is often assumed that astrocyte functions may get out of the balance in pathological situations and then compromise neuronal survival (Buffo et al. 2010). In support of this, altered (i.e., activated) astrocytes are found in many neurodegenerative diseases (Forno et al. 1992; Medeiros and LaFerla 2013; Orre et al. 2014), in intoxications, and after traumatic injury (Silver and Miller 2004).

The different functions of astrocytes may be due to largely different activation states (Avendano et al. 2015; Falsig et al. 2004a; Henn et al. 2011) triggered by neuroinflammatory conditions linked to damage, disease, or infection. The first glial cells to be activated in such conditions are usually microglia. These secrete cytokines like IL-1 $\beta$ and TNF- $\alpha$, which are very potent activators of astrocytes. This large pool of cells then reacts with a second wave of mediators (Falsig et al. 2008) and can remain activated and altered in their function for a long time after stimulation (Biesmans et al. 2015; Henn et al. 2011).

The causal role of astrocytes in disease has been probed by several pharmacological interventions (Kohutnicka 
et al. 1998; Kurkowska-Jastrzebska et al. 2004), and also genetic tools exist to deplete such cells from the brain (Mayo et al. 2014), but the interpretation of such studies is difficult. The pathological and toxicological role of astrocytes may be highly model-specific, as they contribute to the metabolism of some toxicants (Schildknecht et al. 2012) and they show a large plasticity, e.g., by taking the role of stem cells (Robel et al. 2011). Moreover, astrocytes and microglia produce a large variety of different mediators that may affect neurons, e.g., direct excitotoxicants, like glutamate, or indirect excitotoxic mediators, such as NO (Bal-Price and Brown 2001; Bal-Price et al. 2002; Gandelman et al. 2010; Gegg and Clark 1036; Mander et al. 2005), lipid mediators/small molecules (Mayo et al. 2014; Simon et al. 2002; Wang et al. 2012), reactive oxygen species (Ma et al. 2013), proteases (cathepsin B), cytokines (Lee et al. 2013a; Mattson et al. 1997), complement factors (Pekny et al. 2007; Walker et al. 1998), but their respective contribution to human pathology needs further clarification (Lioy et al. 2011; Williams et al. 2014). Lack of knowledge of the relevant damage mediators has prevented the development of targeted therapies for modulation of astrogliosis, but some drugs like riluzole (Carbone et al. 2012) or CEP1347 (Falsig et al. 2004b) have astrocyte-modulating properties besides their main mode of action.

In vitro models allow biochemical studies at cellularlevel analysis, often difficult in complex in vivo situations (Fig. S1). Traditional approaches to study astrocyte-neuron interactions include re-aggregating brain cultures, more defined co-cultures in 2D (Garwood et al. 2011; Sandstrom von Tobel et al. 2014), or 3D formats (Puschmann et al. 2013). An added benefit of defined co-cultures is that human neurons can be studied.

For some applications focusing on the neurodegeneration in co-cultures, immortalized astrocyte cell lines provide a simple, but robust source of astrocytic factors or metabolic capacity (Efremova et al. 2015; Lee et al. 2013a, b) to be tested on associated neurons. In cases where the toxic factors are non-proteinaceous, cells from two different species can be used, and they provide some analytical advantages. For such purposes, IMA can be combined with post-mitotic human neurons, differentiated from the LUHMES cell line (Scholz et al. 2011). These cells are conditionally immortalized, and they assume neuronal morphological, electrophysiological, and neurochemical properties upon the switching off of the v-myc transgene by tetracycline. The cells can be cultured on a layer of astrocytes (Efremova et al. 2015; Kuegler et al. 2012), and they form highly reproducible co-cultures when combined with the immortalized murine astrocytic cell line IMA (Schildknecht et al. 2012). The latter cells can metabolize drugs, such as 1-methyl-4-phenyl-tetrahydropyridine (MPTP), and are well characterized in their inflammatory response. The LUHMES-IMA co-culture allowed multiple pharmacological interventions on the level of neurons and astrocytes (Efremova et al. 2015).

In the present study this experimental system was used to study neuron-glia interactions under inflammatory conditions and to provide a pharmacological characterization of relevant cell responses. In the beginning, we asked whether protection of neurons from toxicants by healthy non-activated glia can be confirmed and quantified. We then proceeded to examine how this situation changes under inflammatory conditions (cytokine exposure). A prolonged activation of astrocytes resulted in neuronal death, mediated by a soluble factor. This system of human neuronal death due to glial activation allowed for the first-time evaluation of several experimental pharmacological approaches targeted to human neurons. The model allows separate testing on the individual cell types (for target and pathway definition) or direct evaluation in co-cultures (for testing of therapeutic effectiveness) in complex settings that allow multiple reciprocal cell interactions.

\section{Materials and methods}

\section{Cell culture}

LUHMES cells were used exactly as described earlier (Scholz et al. 2011). They were maintained in poly-L-ornithine $(50 \mu \mathrm{g} / \mathrm{ml})$ and fibronectin $(10 \mu \mathrm{g} / \mathrm{ml}$, SigmaAldrich, St. Louis, MO, USA)-coated flasks (Nunclon) in proliferation medium containing $40 \mathrm{ng} / \mathrm{ml}$ basic fibroblast growth factor (R\&D Systems). For differentiation, the cells were seeded at a density of $1.5^{*} 10^{5}$ cells per $\mathrm{cm}^{2}$ in differentiation medium containing $1 \mathrm{mM}$ dibutyryl cAMP (Sigma-Aldrich), $10 \mu \mathrm{g} / \mathrm{ml}$ tetracycline (Sigma-Aldrich), and $2 \mathrm{ng} / \mathrm{ml}$ human GDNF (R\&D Systems). The immortalized murine astrocytes (IMA2.1) were passaged in DMEM supplemented with $10 \%$ FCS (fetal calf serum, PAA) and $1 \%$ of penicillin/streptomycin (Schildknecht et al. 2012). Normal human astrocytes (NHA) were purchased from LONZA (catalog number CC-2565, Cologne, Germany) and grown in medium consisting of astrocyte basal medium $\left(\mathrm{ABM}^{\mathrm{TM}}\right.$, catalog number CC-3187, LONZA) supplemented with AGM SingleQuot Kit Supplement \& Growth Factors (catalog number CC-4123, LONZA). Cell cultures were maintained according to the manufacturer's protocol. For co-cultures, IMA $\left(15.000 / \mathrm{cm}^{2}\right)$ or NHA cells $(5.000 /$ $\mathrm{cm}^{2}$ ) were seeded in their proper medium. After $24 \mathrm{~h}$, medium was changed to LUHMES differentiation medium (no FCS, no antibiotics). After additional $48 \mathrm{~h}$, pre-differentiated LUHMES cells (d2) were seeded on top of the now confluent glia layer (counted cell density: $60.000 / \mathrm{cm}^{2}$ ) 
at a density of $150.000 / \mathrm{cm}^{2}$. On day 6 of LUHMES differentiation, experimental treatment was started.

\section{Cell viability assays}

Cellular resazurin reduction capacity was determined by addition of $10 \mu \mathrm{g} / \mathrm{ml}$ reagent to the cells, incubation for $30 \mathrm{~min}$, and measurement of fluorescence at $\lambda_{\mathrm{ex}}=530$ and $\lambda_{\mathrm{em}}>590 \mathrm{~nm}$; lactate dehydrogenase (LDH) release was measured enzymatically (NADH consumption): LDH activity was detected in cell culture medium (supernatant) and cell lysates separately. The percent LDH release was expressed as $100 \times \mathrm{LDH}_{\text {(supernatant) }} /\left(\mathrm{LDH}_{\text {(supernatant) }}+\mathrm{LDH}\right.$ (lysate) (Krug et al. 2014). Release of human-specific neuronal enolase into co-culture supernatants was analyzed using the 'Neuron-specific Enolase' Quantikine ELISA Kit (R\&D, Wiesbaden) according to the manufacturer's protocol. Quantification of neuronal area was based on selective immunostaining (see below) of neuronal BIIItubulin (Tuj1 antibody) and high-content imaging: An Array-Scan VTI HCS Reader (Cellomics, PA) was used for image acquisition. Thirty fields per well $(330 \mu \mathrm{m} \times 330 \mu \mathrm{m}$ size each) were imaged and analyzed (Efremova et al. 2015). The software recognizes the Tuj-positive pixels and calculates the total pixel number per well. Three wells were analyzed for each treatment, and the total pixel number was normalized to the total pixel number of untreated controls. Astrocyte nuclei were counted in monocultures after staining with H-33342. The pictures in ten fields per well were analyzed after observer blinding, and three wells were analyzed for each treatment. In parallel, cells were lysed for protein determination using the Pierce BCA protein assay kit (Thermo Scientific, Rockford, IL, USA).

\section{NO release}

Nitrite $\left(\mathrm{NO}_{2}^{-}\right)$, the stable autoxidation product of $\mathrm{NO}$, was measured by the Griess assay exactly as described earlier (Schildknecht et al. 2012). Nitrite concentrations were calculated from a $\mathrm{NaNO}_{2}$ standard curve.

\section{Immunocytochemistry}

For confocal imaging, cells were grown on poly-ornithine/ fibronectin-coated glass cover slips, washed with PBS, and fixed with $4 \%$ paraformaldehyde (PFA) in $2 \%$ sucrose for 15 min. Cells were permeabilized with $0.2 \%$ Triton X-100 in PBS, washed with $0.05 \%$ Tween 20 in PBS, and blocked with PBS/1 \% BSA (Calbiochem, San Diego, CA, USA) for $1 \mathrm{~h}$ at room temperature (RT). Primary antibodies were incubated overnight at $4{ }^{\circ} \mathrm{C}$. Secondary antibodies were applied for $1 \mathrm{~h}$ (RT) in the dark. Hoechst-33342 (1 $\mu \mathrm{g} / \mathrm{ml}$, Molecular Probes) was added for 15 min prior to the final washing step. Cover slips were mounted on glass slides with FluorSave ${ }^{\mathrm{TM}}$ reagent (Calbiochem). The same procedure was also used for high-content imaging of cells grown directly on coated (poly-ornithine/fibronectin) cell culture plastic, using the murine monoclonal Tuj1 ( $\beta$ IIItubulin; \#MMS435P, Covance; 1:500), and the secondary goat antimouse IgG2a antibody (Alexa-Fluor-555-coupled; 1:1000; \#A-21137, Life technologies). All other antibodies were used here according to the same protocol. They are standard reagents offered by multiple suppliers in often changing qualities. The details on the particular material used here are given in supplemental methods.

\section{Statistics}

Where not indicated otherwise, data are mean \pm SEM of triplicates from different cell preparations. Statistics were done by ANOVA followed by an appropriate post hoc test.

\section{Results}

\section{Astrocytic support of neurons and attenuation of neurotoxicity}

We used here a recently established co-culture model (Efremova et al. 2015) of LUHMES neurons and IMA astrocytes. Three-dimensional imaging by confocal microscopy confirmed that neurons are mostly positioned in a layer above the astrocytes, and that both neurites and somata establish large contact interfaces with astrocytes (Fig. 1a, b). Immunostaining showed that co-cultured LUHMES extended long neurites and expressed tyrosine hydroxylase (TH) as well as the vesicular monoamine transporter like LUHMES monocultures (Fig. S2). We also found that neuronal cultures were more easily maintained in the presence of IMA astrocytes (viability close to $100 \%$ on d 12 of neuronal differentiation) than monocultures (variable viability on d12 with a range of 50-100\%). A comparison of IMA with seven other cell types showed that only glial cells (murine, rat or human astrocytes) supported neurons, while other cells (e.g., astrocytoma or human neuroepithelial cells) did not (Fig. S3).

To examine whether IMA provided also a more active form of protection, we challenged LUHMES neurons by the peroxynitrite donor SIN-1. A significant decrease of neuronal viability was observed in monocultures, whereas neurite integrity and viability of co-cultured neurons were not affected. Astrocytes were not affected by the SIN-1 concentrations used here. Encouraged by these findings, we tested three different neurotoxicants and quantified neuronal viability/network complexity by $\beta$ IIItubulin staining. At a low concentration of $1 \mu \mathrm{M}$, the specific dopaminergic 


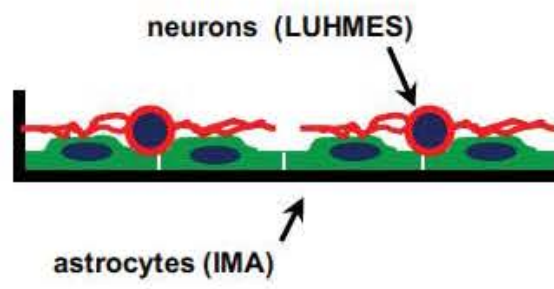

b

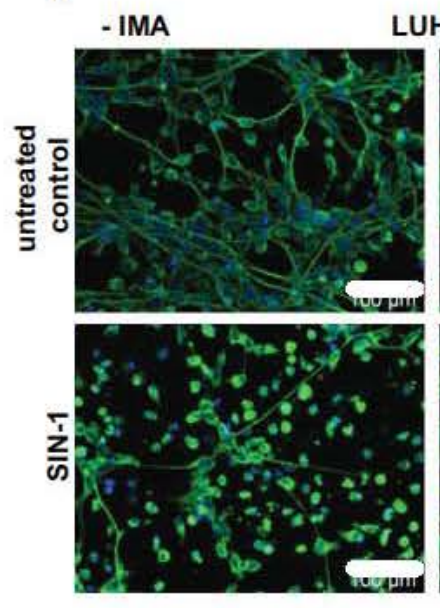

UHMES

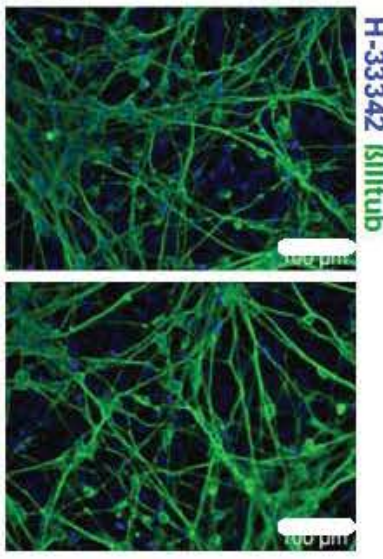

C

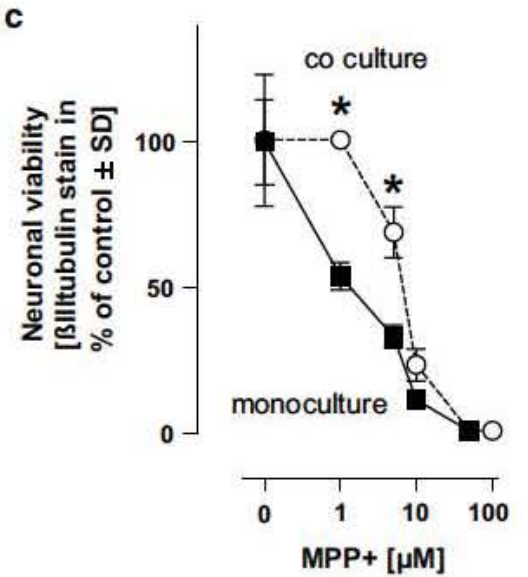

Fig. 1 Alteration of neurotoxicity by co-cultivation with glial cells. a Human neurons (derived from LUHMES cells) were cultivated on top of a layer of immortalized murine astrocytes (IMA) as indicated in the scheme. Cultures of LUHMES and IMA were stained on day 4 of co-cultivation, i.e., d6 of LUHMES differentiation for the neuronalspecific marker Tuj1 ( $\beta$ IIItubulin, red), the astrocyte-specific marker S100ß (green), and with the DNA stain H-33342 (blue). A Z-stack of images was recorded on a confocal microscope (scale bar $=20 \mu \mathrm{m}$ ). The $x-z$ and $y-z$ sections show the localization of neurons and astrocytes in different focal planes (as schematically shown). b LUHMES

neurotoxicant $\mathrm{MPP}^{+}$led to a $50 \%$ decrease of neuronal area, while viability was fully maintained in the presence of IMA. At higher concentrations ( $5 \mu \mathrm{M})$, IMA provided partial protection, and at even higher concentrations ( $\geq 10 \mu \mathrm{M}$; never reached in vivo) the protective effect was eventually lost. For the peroxynitrite donor SIN-1 and the
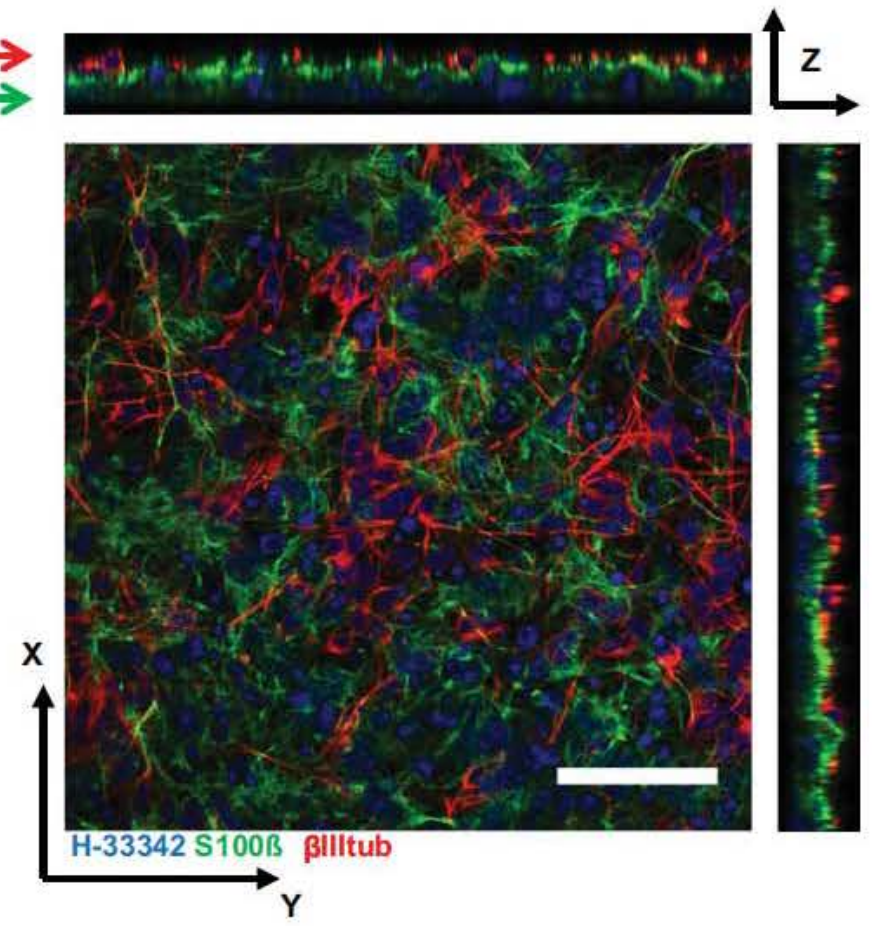

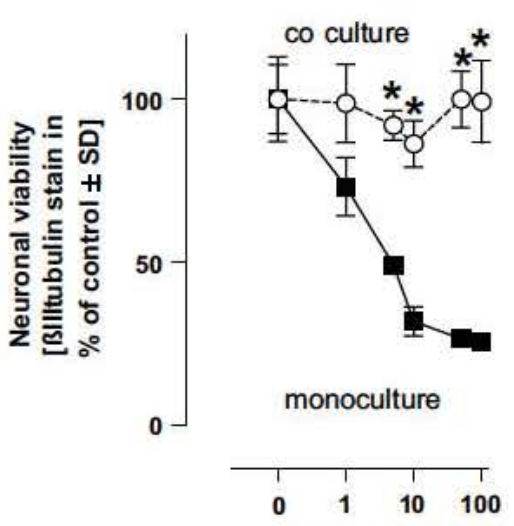

SpermineNONOate $[\mu \mathrm{M}]$

monocultures (d6, '-IMA') or IMA-LUHMES co-cultures (d6 of LUHMES, '+IMA') were exposed to SIN-1 $(1000 \mu \mathrm{M})$ for $24 \mathrm{~h}$. Then, cells were fixed and stained to visualize $\beta$ IIItubulin (green) and nuclei (H-33342, blue); scale bar $=100 \mu \mathrm{m}$. c LUHMES monocultures and co-cultures (d6) were exposed to various concentrations of MPP+ $(0-100 \mu \mathrm{M})$, SIN $-1(0-1000 \mu \mathrm{M})$, and spermineNONOate $(0-100 \mu \mathrm{M})$ for $24 \mathrm{~h}$. Then, cells were fixed and stained for BIIItubulin, and the $\beta$ IIItubulin-positive neuronal area was quantified by an automated imaging procedure. Data are expressed as mean \pm SD of quadruplicates; ${ }^{*} p<0.05$ (co-culture vs. monoculture) (color figure online)

NO-releasing agent spermineNONOate, full protection by IMA was observed even at concentrations that killed $>90 \%$ of monocultured neurons (Fig. 1c). These data are in good agreement with many literature findings of astrocytic support of neurons, e.g., by provision of glutathione precursors (Pizzurro et al. 2014) or other mechanisms. 
Switching from neuroprotective to neurotoxic properties of astrocytes exposed to pro-inflammatory cytokines

To model an inflammatory situation, as it occurs during brain damage and neurodegenerative disease, we used a cytokine mix (TNF- $\alpha$ and IL-1 $\beta$ ) known to be produced in neuroinflammatory situations (mainly by microglia) and known to activate astrocytic cells, including IMA (Falsig et al. 2006; Henn et al. 2011; Kuegler et al. 2012; Schildknecht et al. 2012). This CM had no effect on the viability and neurite structure of LUHMES monocultures (Fig. S4a). The absence of an effect was confirmed even when a third cytokine, IFN- $\gamma$, was added to CM (Fig. S4b). Moreover, CM did not affect the toxicity of SIN-1 or NO in LUHMES monocultures (Fig. S4c).

Having established that CM treatment does not affect neurons directly, we tested whether it would alter the protective effect of glia in co-cultures. To this end, we exposed cells to $\mathrm{CM}$ at $24 \mathrm{~h}$ before the treatment with toxicants (1 mM SIN$1,100 \mu \mathrm{M}$ spermineNONOate). The CM reduced the neuroprotective effect of IMA significantly (Fig. 2a).

While short exposure ( $<3$ days) to $\mathrm{CM}$ did not reduce neuronal viability in co-cultures (but reduced glial protection from $\mathrm{NO}$ ), exposure to $\mathrm{CM}$ for 6 days led to pronounced neurodegeneration without any other toxicant added (Fig. 2b). As standard endpoint to quantify neurodegeneration in co-cultures, we used specific staining of $\beta$ IIItubulin and an automated algorithm to quantify the overall neuronal area (Efremova et al. 2015). This endpoint correlated with the measurement of the release of neuronspecific enolase (Fig. 2c). This glycolytic isoenzyme, which is widely used as a specific read out for the assessment of neuronal damage level, is only expressed in neurons, but not in glial cells.

In order to find out which cytokine was involved in glial cell-mediated neurodegeneration, we exposed LUHMESIMA co-cultures to IL- $1 \beta$, TNF- $\alpha$, and IFN- $\gamma$ individually, and in combinations. Both IL- $1 \beta$ and TNF- $\alpha$ were able to trigger the degenerative response, while IFN- $\gamma$ was without effect (Fig. 2d). To ensure a robust response, we selected the combination of TNF- $\alpha$ and IL-1 $\beta$ (=CM) for our further experiments.

\section{Signaling events occurring in reactive astrocytes exposed to cytokines}

To obtain direct evidence on the stimulation of IMA by $\mathrm{CM}$, they were examined in the absence of neurons. After 2-day exposure, the cultures started to change morphology. On day 6 all cells were elongated and orientated along parallel lines (Fig. 3a). This change was accompanied by other common features of reactive astrocytes, such as increased protein content and proliferation. The immediate cytokine response (within $30 \mathrm{~min}$ ) was reflected by NF-kB translocation (Fig. 3b-d).

As NO is a candidate for glia-dependent neurotoxicity (Brown and Neher 2010), we examined the production of this mediator, but nitric oxide was not produced. For control purposes, IFN- $\gamma$ was added to the CM, and under these altered conditions, pronounced and continuous (over 5 days) NO production was measured (Fig. 3e). We conclude from this, and from the absence of any protective effect of nitric oxide synthase inhibitors (Fig. S5), that NO is unlikely to be involved in the neurodegeneration observed in our model.

\section{Pharmacological protection of neurons from cytokine toxicity in co-cultures}

To obtain additional evidence on the inflammatory nature of neurodegeneration in the LUHMES-IMA-CM model, we tested the effect of the anti-inflammatory corticosteroid dexamethasone. This drug had been shown to protect DA neurons in the in vivo MPTP model via a decrease of the inflammatory reaction of glial cells (Kurkowska-Jastrzebska et al. 2004). We also observed complete protection from CM toxicity (Fig. 4a). As this required high micromolar concentrations, we tested whether the protection was glucocorticoid receptor-dependent or may involve, e.g., antioxidant steroid effects (Hansson et al. 2000). To this end, we used the glucocorticoid receptor antagonist mifepristone. Mifepristone alone had no effect at all on neuronal viability, but it fully abolished the protective effect of dexamethasone (Fig. 4b).

In contrast to the broadly acting corticosteroid, several other treatments that specifically affect certain inflammatory pathways did not alter neuronal survival: inhibitors of NF-kB, of cyclooxygenases, or of protein/cytokine secretion. However, concentration-dependent protection was observed, when the p38 MAP kinase inhibitor SB202190 was used (Fig. 4c). Thus, our model allows exploration of glio-modulatory drug candidates, with dexamethasone and SB202190 as positive control.

\section{Essential reproduction of model features after substitution of IMA by human astrocytes}

Although the use of murine IMA cells for the co-culture model has many advantages (robustness, ease of preparation, easy analysis of specific cell responses on mRNA, and protein level) (Efremova et al. 2015), there may be situations that would require human astrocytes (e.g., characterization of certain biologics drugs). Moreover, we wanted to be sure that the effect observed was not an interspecies artifact, but reproducible with human astrocytes. Therefore, we 

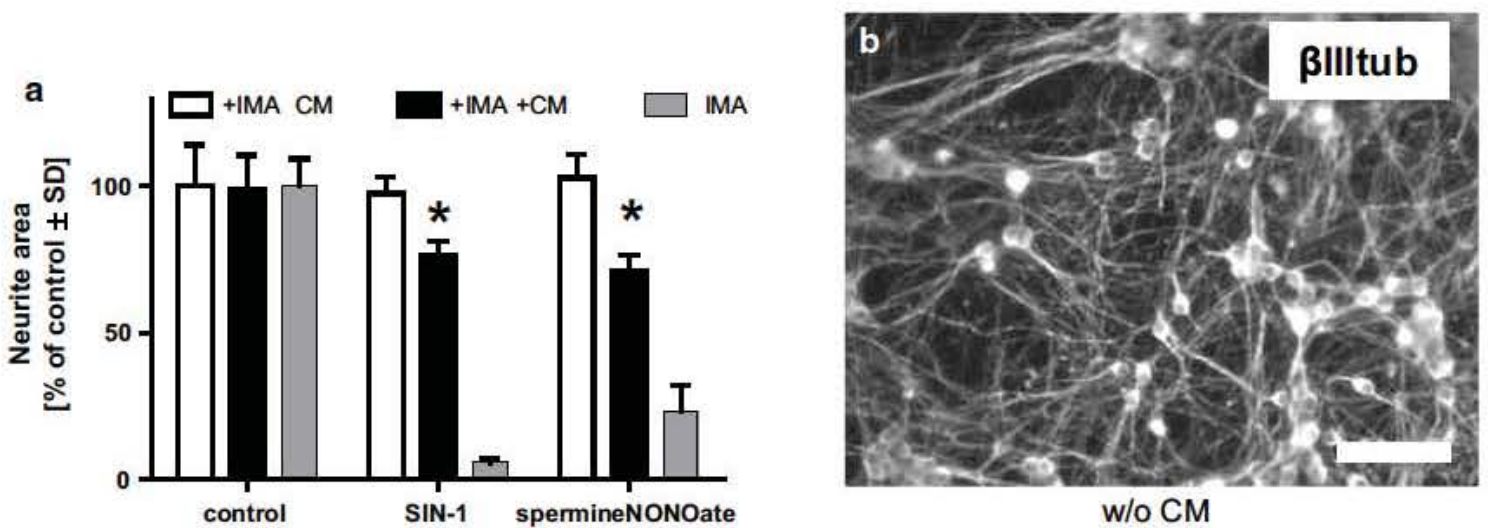

w/o CM
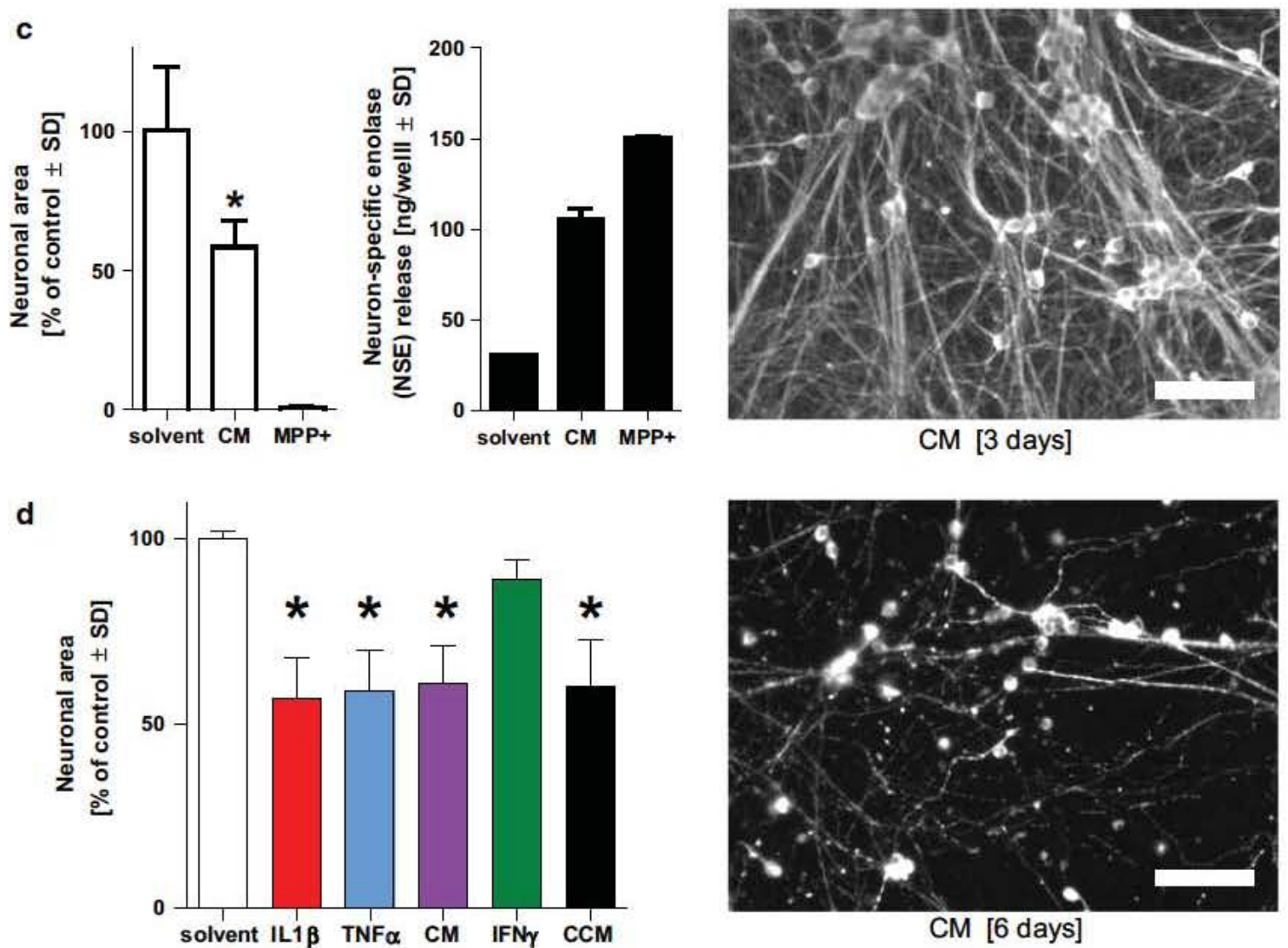

Fig. 2 Switching from neuroprotective to neurotoxic properties of glia by exposure to inflammatory cytokines. a Co-cultures of d6 LUHMES and IMA (+IMA) and d6 LUHMES monocultures (-IMA) were either left untreated $(-\mathrm{CM})$ or exposed for $24 \mathrm{~h}$ to a cytokine mix $(+\mathrm{CM})$ consisting of murine IL-1 $\beta(10 \mathrm{ng} /$ $\mathrm{ml})+$ murine TNF- $\alpha(10 \mathrm{ng} / \mathrm{ml})$ before they were treated with solvent (control), SIN-1 $(1000 \mu \mathrm{M})$, or spermineNONOate $(100 \mu \mathrm{M})$ for additional $24 \mathrm{~h}$. Then, cells were fixed and stained for $\beta$ IIItubulin, and the $\beta$ IIItubulin-positive neuronal area was quantified by an automated imaging procedure; ${ }^{*} p<0.05$ (exposed to $\mathrm{CM}$ vs. unexposed). b IMA-LUHMES co-cultures (d6) were exposed to CM for 3 or 6 days. Then, neurons were stained for $\beta$ IIItubulin, and images were recorded on a fluorescent microscope; scale bar $=100 \mu \mathrm{m}$. c IMALUHMES co-cultures (d6) in 24 well plate were exposed to CM or

to $10 \mu \mathrm{M} \mathrm{MPP}+$. After 6 days, cultures were stained for $\beta$ IIItubulin, and the $\beta$ IIItubulin-positive neuronal area was quantified by an automated imaging procedure. The release of human neuron-specific enolase (NSE) was measured in culture supernatants. The total amount of NSE in culture supernatants of control cultures was $8.5 \pm 1 \mathrm{ng} /$ $\mathrm{ml}$ culture supernatant; $t$ test, ${ }^{*} p<0.05$ (CM vs. solvent). d IMALUHMES co-cultures (d6) were exposed to murine $I L-1 \beta(10 \mathrm{ng} / \mathrm{ml})$, murine TNF- $\alpha(10 \mathrm{ng} / \mathrm{ml})$, murine IFN- $\gamma(20 \mathrm{ng} / \mathrm{ml})$, to CM, or to a complete cytokine mix (CCM: IL- $1 \beta+$ TNF- $\alpha+$ IFN- $\gamma$ ) for 6 days. Then, cultures were stained for $\beta$ IIItubulin, and the neuronal area was measured by an automated imaging procedure. Data are expressed as mean \pm SD of quadruplicates; Dunnett's multiple comparison test, ${ }^{*} p<0.05$ (all bars vs. solvent) 


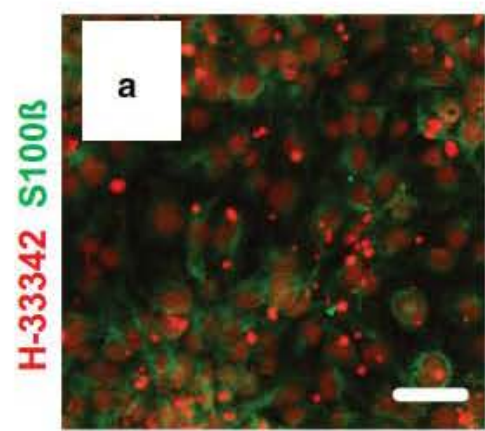

w/o CM [6days]

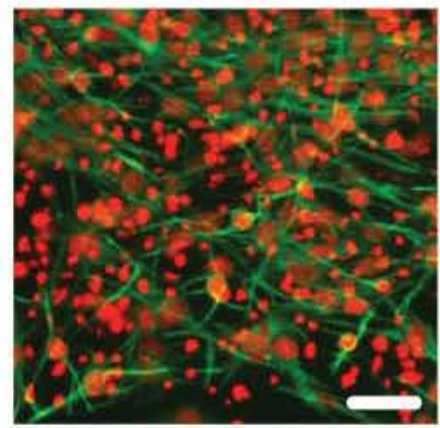

CM [4 days]

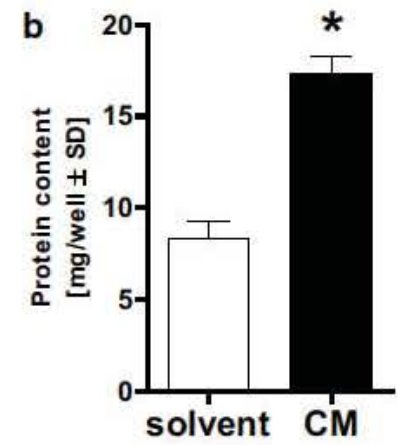

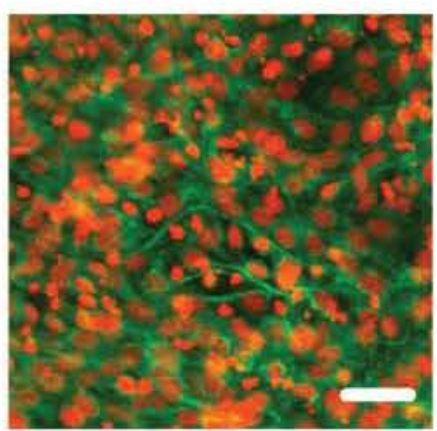

CM [2 days]

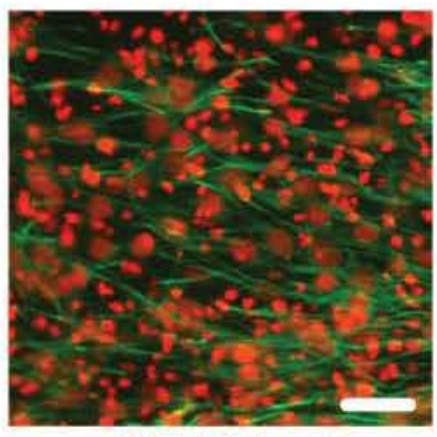

CM [6 days]

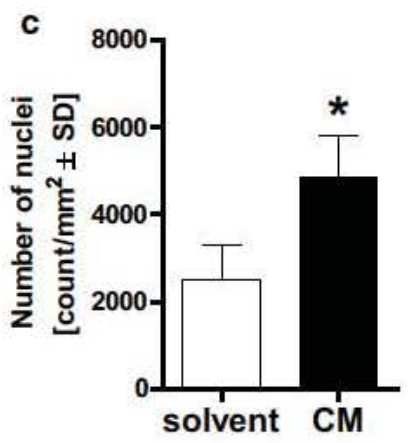

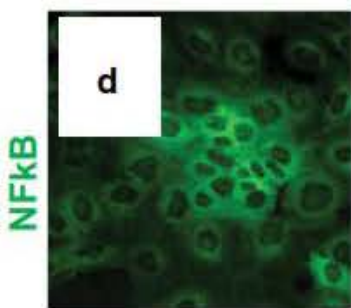
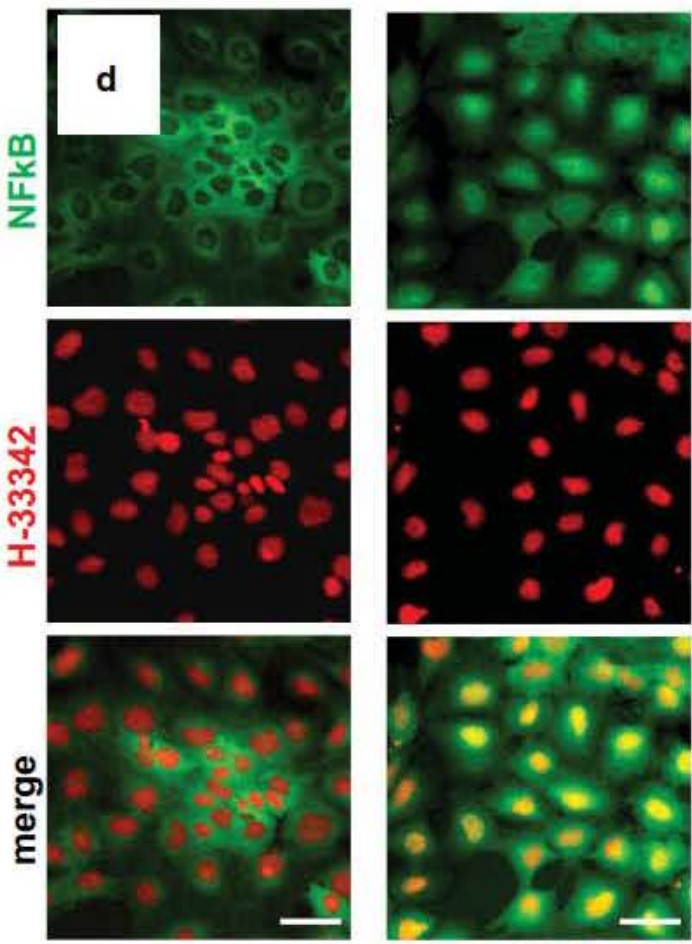

solvent

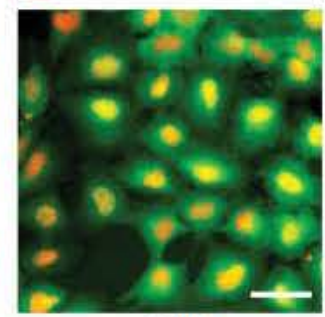

CM

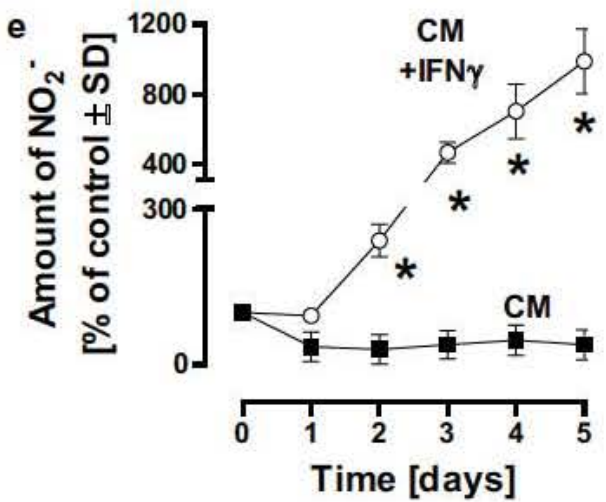

Fig. 3 Astrocyte activation and proliferation by exposure to cytokine mix (CM). a IMA monocultures were exposed to murine CM (IL$1 \beta+$ TNF- $\alpha$ ) for 2,4 , and 6 days. Then, cells were fixed, permeabilized, and immunostained for the astrocyte-specific marker $S 100 \beta$ (green); nuclei were stained with H-33342 (red), scale bar $=100 \mu \mathrm{m}$. b IMA cells were exposed to CM for 6 days. Then cells were lysed, and the protein amount in lysates was assessed; $t$ test, ${ }^{*} p<0.05$ (solvent vs. CM). c For assessment of the number of nuclei, IMA monocultures were fixed and stained with $\mathrm{H}-33342$ after 6 days of CM exposure. Ten fields (each $330 \mu \mathrm{m} \times 330 \mu \mathrm{m}$ size each) per well were imaged in one channel using a $20 \times$ objective. The pictures were then analyzed by software, which recognized the H-33342-positive nuclei

substituted IMA for human astrocytes (NHA) and tested their response to the human version of CM. Upon stimulation, they underwent a morphological change similar to IMA (spindle-shaped, parallel-oriented cells) and triggered degeneration of LUHMES cells (Fig. 5a). Already after and calculated their number in each field. Three wells of 24 well plates were analyzed for each treatment conditions; $t$ test, ${ }^{*} p<0.05$ (solvent vs. CM). d IMA monocultures were stimulated with $\mathrm{CM}$ or solvent for $30 \mathrm{~min}$. Then cells were stained with an anti-NF-kB p65 antibody (green), and nuclei were stained with H-33342 (red). Images were taken by using a fluorescent microscope, scale bar $=100 \mu \mathrm{m}$. e IMA cells were exposed to CM (TNF- $\alpha+\mathrm{IL}-1 \beta$ ) with or without IFN- $\gamma$. The nitrite concentrations in the cell culture supernatant were measured by using the Griess method. Nitrite served as an indicator for NOS activity and subsequent NO release. Data are expressed as mean \pm SD of quadruplicate samples; Bonferroni's test, ${ }^{*} p<0.05$ (solvent vs. CM) (color figure online)

4 days, $>50 \%$ neurodegeneration was observed (Fig. 5b). As in the IMA model, full protection by dexamethasone was observed (Fig. 5c). In summary, human astrocytes behaved similar to IMA concerning major features of the co-culture cytokine-mediated neurodegeneration. 

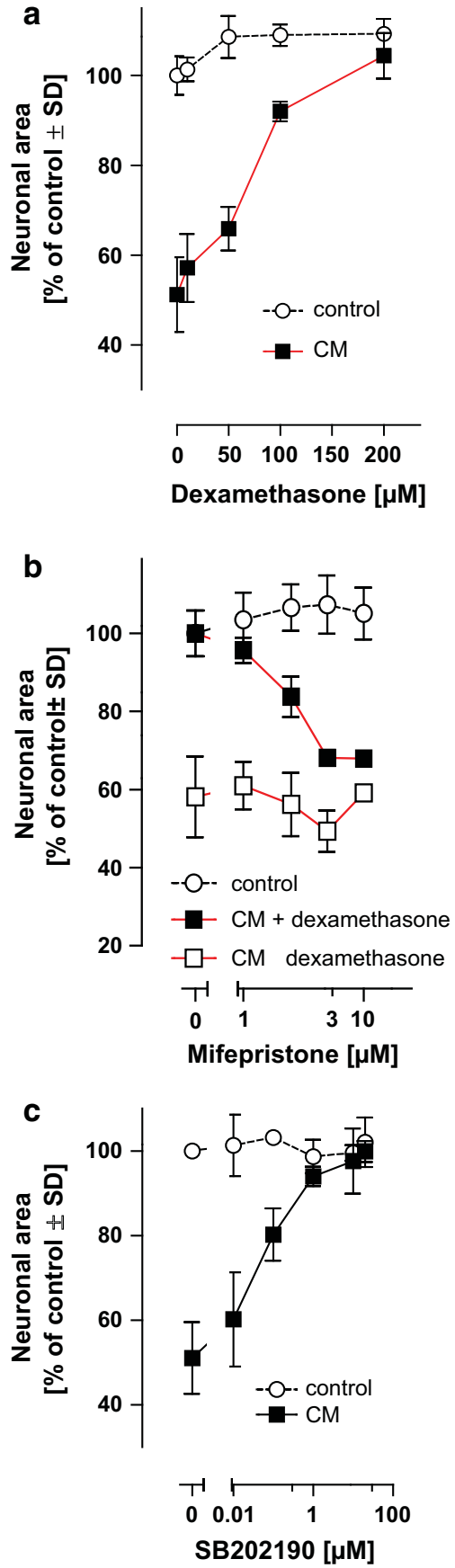

\section{Neurotoxicity triggered by activated glia through the activity of soluble factors}

In order to assess whether soluble transferrable factors play a role in neurotoxicity mediated by activated glia, IMA monocultures were exposed to CM, and conditioned medium was collected. It was transferred to LUHMES monocultures, and immunostaining showed that after 3 days, about $50 \%$ of the neurons had died (Fig. 6a). Measurements of the viability by resazurin (not shown) or quantification of the neuronal area confirmed neuronal
4Fig. 4 Protection from cytokine toxicity in co-cultures by antiinflammatory treatment. a Co-cultures of IMA and LUHMES (d6) were pre-treated with various dexamethasone concentrations $(0-200 \mu \mathrm{M})$ for $30 \mathrm{~min}$, followed by the addition of $\mathrm{CM}$ $(=\mathrm{TNF}-\alpha+\mathrm{IL}-1 \beta)$ or left untreated (control) for 6 days. Then, the cultures were stained for $\beta$ IIItubulin, and the $\beta$ IIItubulin-positive neuronal area was quantified by an automated imaging procedure. b Cocultures were pre-treated for $30 \mathrm{~min}$ with different concentrations of mifepristone $(0-10 \mu \mathrm{M})$ and left untreated (control) or treated with $\mathrm{CM}$ in the absence (CM- dexamethasone) or presence of $100 \mu \mathrm{M}$ dexamethasone (CM+ dexamethasone) for 6 days. Then, the neurite integrity was evaluated by staining for $\beta$ IIItubulin and quantification of the BIIItubulin-positive neuronal area. c Co-cultures were pretreated as in a with various concentrations of SB202190 for $30 \mathrm{~min}$ and exposed to CM for 6 days. Then, viability was measured. Data are expressed as mean $\pm \mathrm{SD}$ of triplicate samples

death triggered by $\mathrm{CM}$ supernatants, but not control supernatants from IMA (Fig. 6b). Time course experiments of supernatant sampling indicated that maximal neurotoxic activity of the IMA medium was reached after about 5 days (Fig. 6c). Freezing and storage for up to 2 weeks had no effect on this activity, but dilution with fresh culture medium led to a reduction of neurotoxicity (Fig. 6d). For practical purposes, 3 parts of IMA supernatants were diluted with 1 part of fresh medium for all following experiments. The astrocyte density used for production of conditioned medium did not play a major role in the range of 7.5-30.000 cells $/ \mathrm{cm}^{2}$. At higher cell densities, also control supernatants became toxic to neurons (Fig. S6). At the production conditions used here (15.000 IMA $/ \mathrm{cm}^{2}$ ), we examined whether the composition of conditioned medium changed drastically. As elevated extracellular L-glutamate (L-Glu) content has been reported in previous inflammation models (Castillo et al. 2002; Ward et al. 2009), we also investigated whether this could be the cause of neurotoxicity in our model. Amino acid analysis showed that cytokine-conditioned medium differed for few amino acids from control supernatant, but many constituents, including L-Glu, remained largely unchanged (Fig. S7a). Application of exogenous L-Glu to the medium had no effect on LUHMES viability (Fig. S7b), and the absence of any neuroprotection from CM-treated IMA supernatant after treatment with glutamate receptor antagonist MK801 further suggested that L-Glu is not likely to play a role in CM-glia-induced neurotoxicity in our model (Fig. S7c). We further checked whether re-addition of factors important for neuronal viability, and possibly depleted by IMA, would alter the toxicity of the conditioned supernatant. However, no effect was observed for GDNF, N2 supplement, pyruvate, or glucose (Fig. S7d). Thus, presence of a factor produced by IMA upon cytokine stimulation is the most straightforward explanation for neurotoxicity of the conditioned medium. 

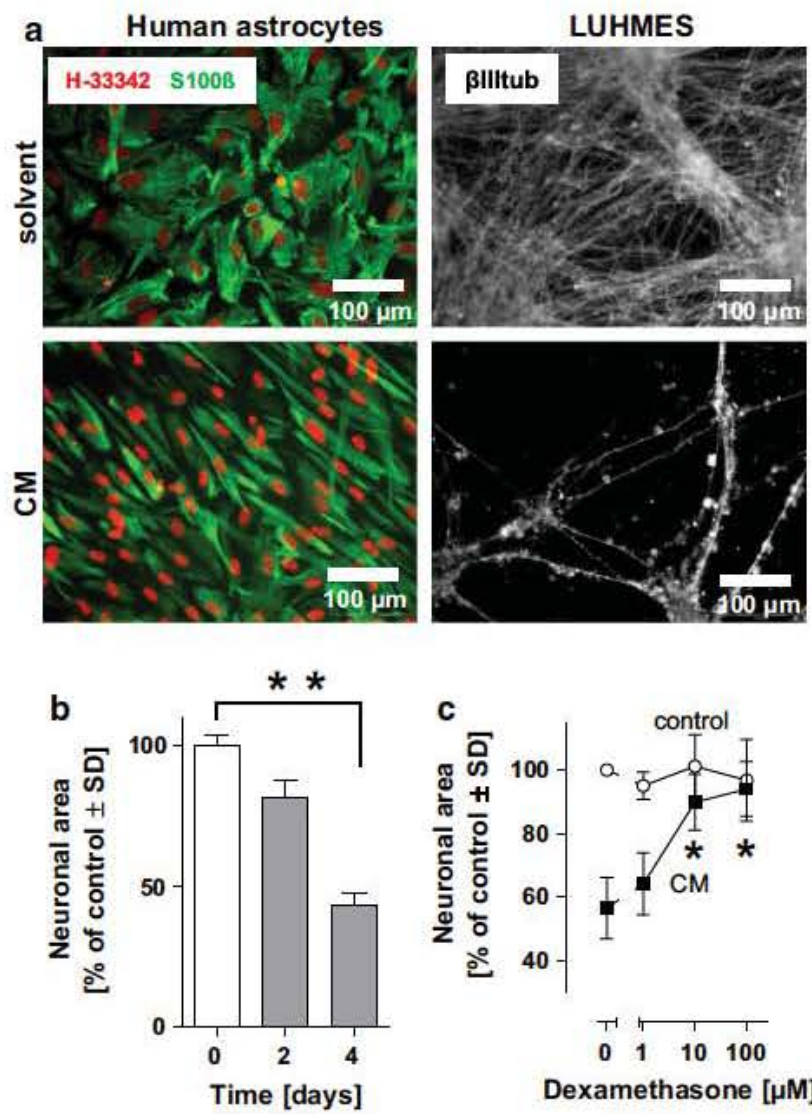

Fig. 5 Cytokine toxicity in human neuron-astrocyte co-cultures. a Human neurons (LUHMES) were cultivated on top of a confluent layer of normal human astrocytes (NHA). Co-cultures of NHA and LUHMES cells (d6) were exposed to CM (human $10 \mathrm{ng} / \mathrm{ml}$ IL- $1 \beta+$ human $10 \mathrm{ng} / \mathrm{ml}$ TNF- $\alpha$ ) for 4 days. Then, co-cultures were stained for the neuronal-specific marker Tuj1 ( $\beta$ IIItubulin, $b / w$ ), the astrocyte-specific marker S100ß (green), and the DNA stain H-33342 (red). Images were recorded on a fluorescent microscope. b NHALUHMES co-cultures were exposed to human CM for 2 or 4 days. Cultures were stained for $\beta$ IIItubulin, and the $\beta$ IIItubulin-positive neuronal area was quantified by an automated imaging procedure; ${ }^{* *} p<0.01$ (control vs. human CM exposure for 4 days). c Co-cultures (d6 of LUHMES, + NHA) were pre-treated with various dexamethasone concentrations $(0-100 \mu \mathrm{M})$ followed by the addition of human $\mathrm{CM}$ for 4 days. Then, cultures were stained for $\beta$ IIItubulin, and the $\beta$ IIItubulin-positive neuronal area was quantified by an automated imaging procedure. Data are expressed as mean \pm SD of triplicate samples; ${ }^{*} p<0.05$ (treated with dexamethasone vs. untreated) (color figure online)

\section{Pharmacological protection from glia-conditioned} neurotoxic medium

The possibility to separate IMA stimulation and neuronal exposure physically allowed now a pharmacological characterization of the neurodamaging effects of astrocytes on the level of the target cell. We used this big advantage of the new model for some targeted interventions (Fig. 7). Boiling of conditioned medium did not decrease its toxic properties. This suggests that factors different from proteins are responsible for the neurotoxic effect. Dexamethasone did not protect LUHMES from glia-conditioned supernatants. Thus, its effect in the co-cultures was most likely due to immunomodulation of the glia. The same was observed for the p38 kinase inhibitor SB202190.

Neither the antioxidant tripeptide GSH nor its oxidized variant (GSSG) showed a protective effect. In this respect, the toxicity of conditioned supernatant differed from MPTP toxicity in LUHMES-IMA co-cultures where GSSG showed a powerful neuroprotection (Efremova et al. 2015). Anti-inflammatory compounds such as NF-kB inhibitors and cyclooxygenase inhibitors (Fig. S5) did not show protection; neither did the ROCK inhibitors Y-27632 (Fig. 7a) and HA-077 (not shown). The latter finding was in contrast to the MPTP model, where both compounds were very efficacious (Efremova et al. 2015).

However, several other compounds protected very efficiently from the toxicity of IMA/cytokine-conditioned supernatant: the $\mathrm{H}_{2} \mathrm{~S}$ donor ATB-337, high concentrations of GDNF ( $100 \mathrm{ng} / \mathrm{ml}$; N.B.: $50 \times$ higher than the normal medium concentration), the phenolic plant ingredient resveratrol, the caspase inhibitor $\mathrm{zVAD}$, and the mixed-lineage kinase inhibitor CEP1347 (Fig. 7a). More detailed concentration-response studies confirmed all initial findings (Fig. 7b). These data suggest the activation of several pathways known to be associated with neurotoxicity. Targeting of such pathways may result in new approach to modify detrimental effects of neuroinflammation.

\section{Pharmacological prevention of glial neurotoxicant production}

An important control of the sequential model of IMA activation and supernatant transfer is the effect of dexamethasone. This drug acted in co-cultures, but not on LUHMES cells. It would therefore be expected that the drug would act during the phase of IMA stimulation, and this was tested in a new pharmacological setup. The drug was co-incubated with CM during the phase of IMA stimulation (Fig. 8a). This conditioned supernatant was not toxic to neurons. A transfer of the drug from IMA onto neurons cannot be avoided in this setup, but as dexamethasone alone had no protective effect, when applied directly on LUHMES, we conclude that it must have acted on IMA. In these studies, the effects of the steroid were observed already in a submicromolar range (Fig. 8b). Thus, dexamethasone showed its expected pharmacological potency in this sequential model, while the co-culture had right-shifted the concentrationresponse considerably.

Encouraged by these findings, we tested the effect of p38 MAP kinase inhibition, which also did not affect neurons alone (medium transfer model), but had protected LUHMES in co-cultures. Two p38 inhibitors reduced neurotoxicity 

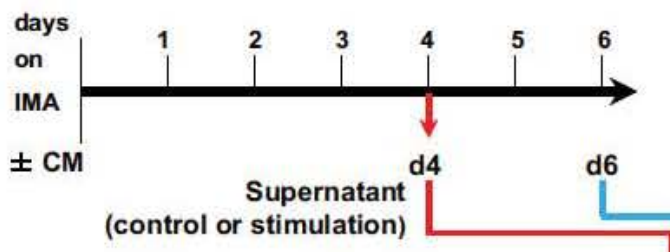

Pre-differentiated for 6 days

LUHMES

a
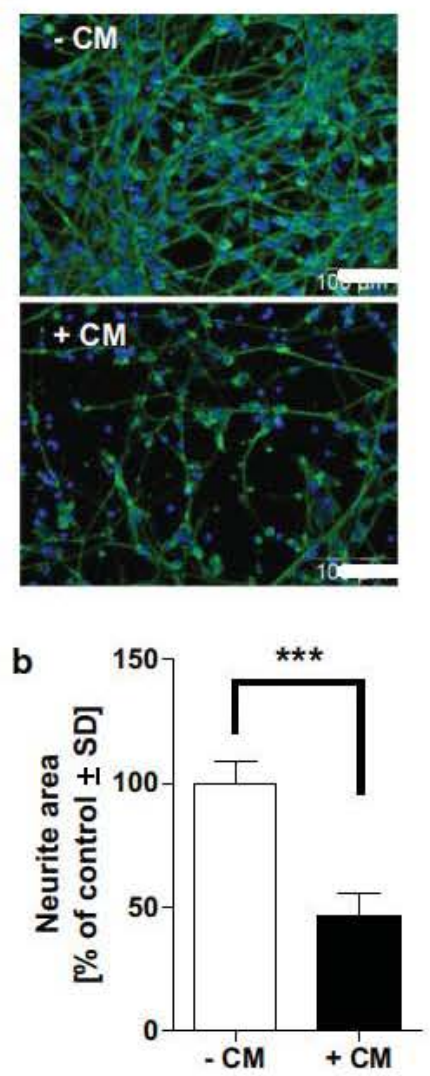
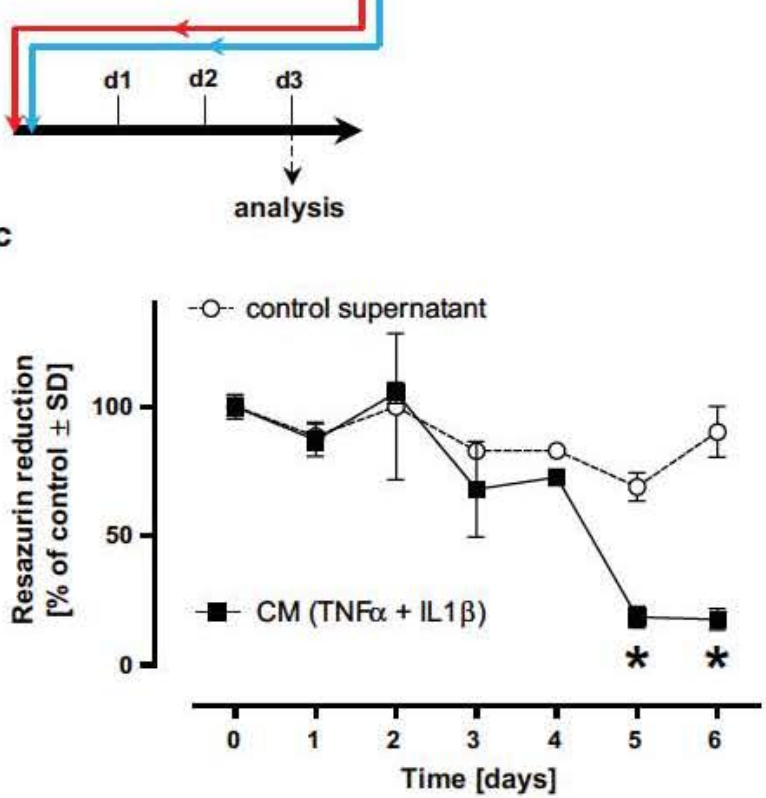

d

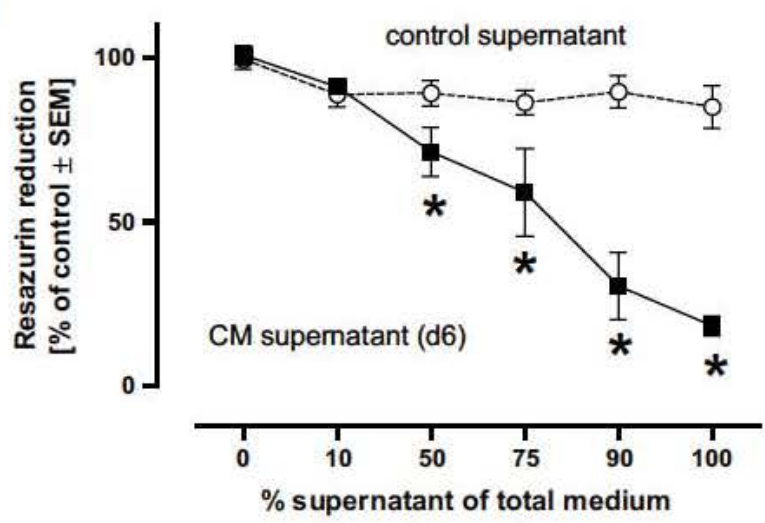

Fig. 6 Mediation of neurotoxicity of inflammatory astrocytes by soluble, transferrable factors. a IMA monocultures were exposed to $\mathrm{CM}$ for 6 days. Then, conditioned medium was collected, diluted $(3+1)$ with fresh LUHMES differentiation medium, and transferred to d6 LUHMES for 3 additional days. Afterward, cells were fixed and stained for $\beta$ IIIt tubulin (green) and the DNA stain H-33342 (blue), and images were recorded on a fluorescent microscope. Scale bar $=100 \mu \mathrm{m}$. b The $\beta$ IIItubulin-positive neuronal area from a was quantified by an automated imaging procedure. Data are expressed as mean $\pm \mathrm{SD}$ of triplicate samples; $t$ test, ${ }^{* * *} p<0.001(-\mathrm{CM}$ vs. $+\mathrm{CM}$ ). c IMA monocultures were incubated in the presence or absence of murine CM. Each 24-h (within the time period of 6 days) conditioned medium from untreated (dashed line, control super- natant) and treated (black line, CM) IMA was collected, filtered, and frozen at $-20{ }^{\circ} \mathrm{C}$. After, conditioned medium was thawed, and $100 \%$ of it was transferred to LUHMES monoculture (d6) for following 3 days. Then, the neuronal viability was measured by the resazurin reduction assay. Data are expressed as mean \pm SD of quadruplicates; two-way ANOVA followed by a post hoc Bonferroni's test, ${ }^{*} p<0.001$ (control supernatant vs. CM). d IMA were exposed to CM for 6 days; then, different amount of conditioned medium $(0-100 \%$ of total medium) was transferred to d6 LUHMES cells for following 3 days. The viability was measured by the resazurin reduction assay. Data are mean \pm SEM of three different experiments; two-way ANOVA followed by a post hoc Bonferroni's test, ${ }^{*} p<0.05$ [control supernatant (d6) vs. CM supernatant (d6)] (color figure online) 


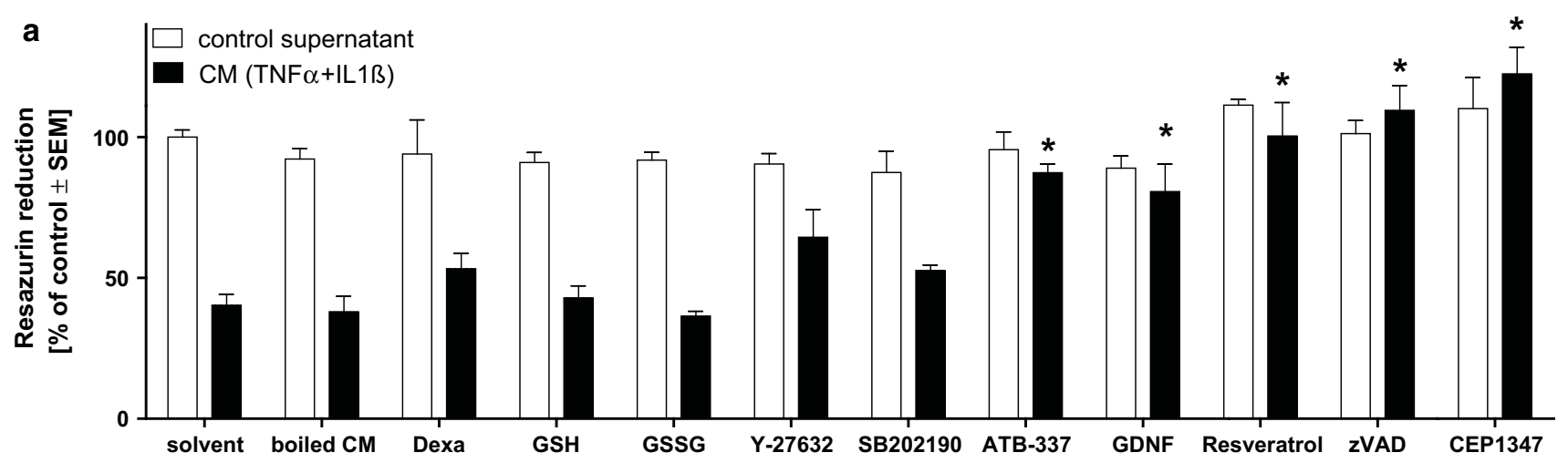

b
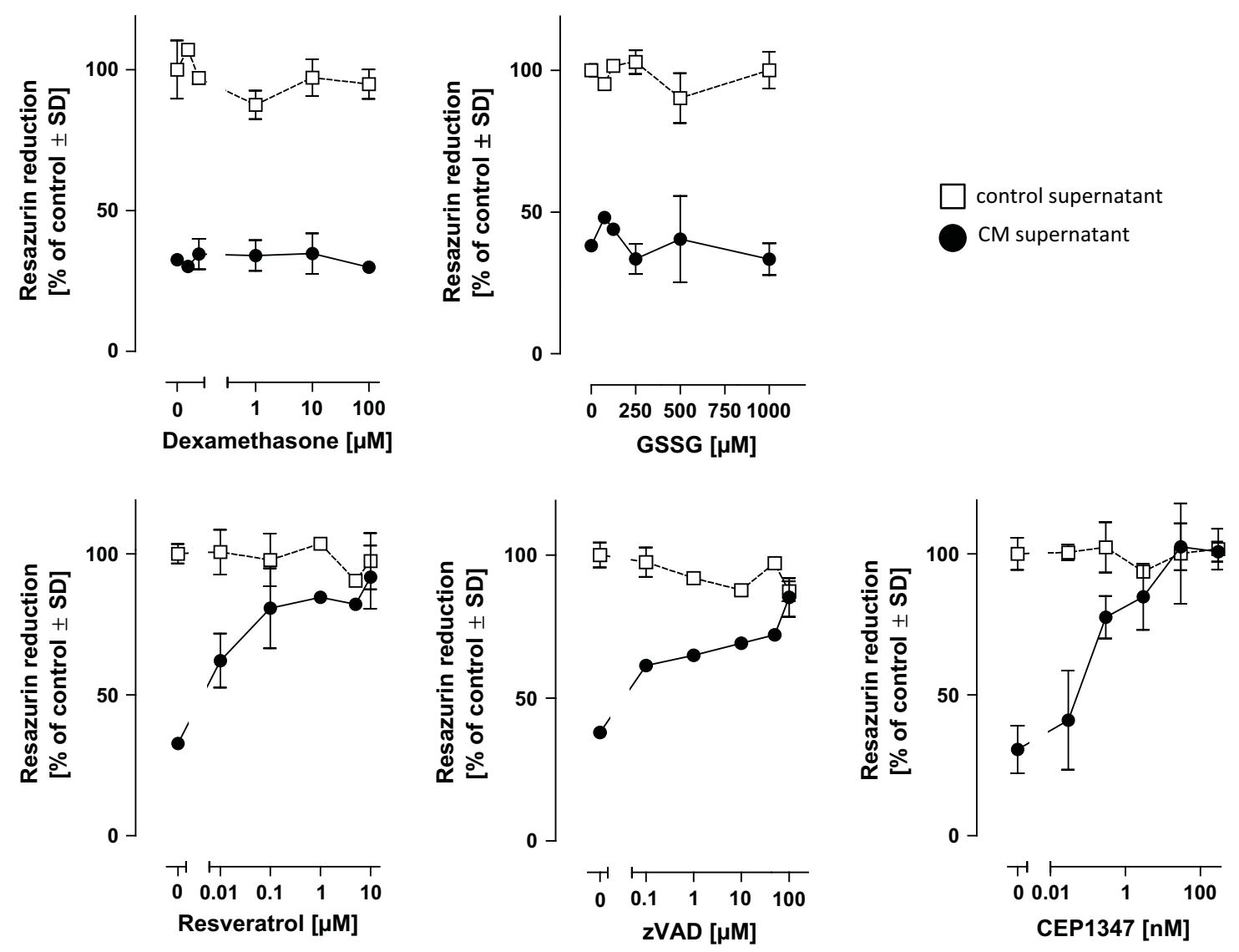

Fig. 7 Pharmacological protection from glia-conditioned neurotoxic medium. a Three parts of conditioned medium from control IMA monocultures (control supernatant) or IMA exposed to CM for 6 days were mixed with one part of fresh LUHMES differentiation medium and used to culture d6 LUHMES monoculture for 3 days. This medium was supplemented with putative neuroprotective compounds: dexamethasone $(100 \mu \mathrm{M})$, GSH $(100 \mu \mathrm{M})$, GSSG $(100 \mu \mathrm{M})$, the p38 kinase inhibitor SB202190, Y-27632 $(10 \mu \mathrm{M})$, the H2S donor ABT-337 $(10 \mu \mathrm{M})$, glial-derived neurotrophic factor (GDNF, $100 \mathrm{ng} /$ $\mathrm{ml})$, resveratrol $(1 \mu \mathrm{M})$, the caspase inhibitor $\operatorname{zVAD}(100 \mu \mathrm{M})$, the

mixed-lineage kinase inhibitor CEP1347 (300 nM). Alternatively, it was boiled $\left(10 \mathrm{~min}\right.$ at $\left.100{ }^{\circ} \mathrm{C}\right)$. The neuronal viability was measured by the resazurin reduction assay. Data are mean \pm SEM of three different experiments; $* p<0.05$ (control supernatant vs. CM supernatant). b Conditioned medium as in a from control or CM-exposed IMA was transferred to d6 LUHMES monocultures, and various concentrations of drugs were added: dexamethasone, GSSG, resveratrol, zVAD, CEP1347. After 3 days, the neuronal viability was measured by the resazurin reduction assay. Data are expressed as mean \pm SD of triplicate samples from one experiment

of glia-conditioned medium in the submicromolar range (Fig. 8c). These data show that drugs targeting specific regulation of inflammatory responses in astrocytes may have neuroprotective potential in neuroinflammatory conditions.

\section{Discussion}

Our study provides clear evidence that activation of astrocytes not only reduces their neuroprotective properties, but 
a

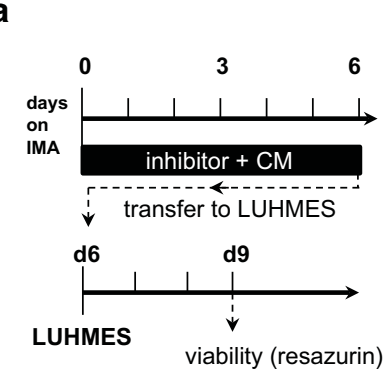

b

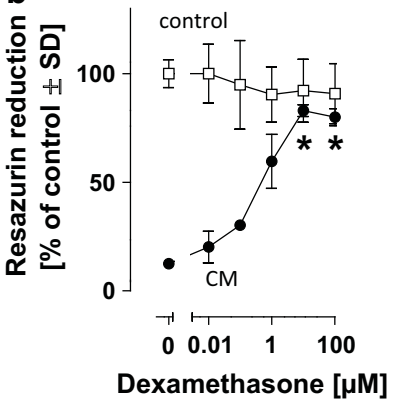

C
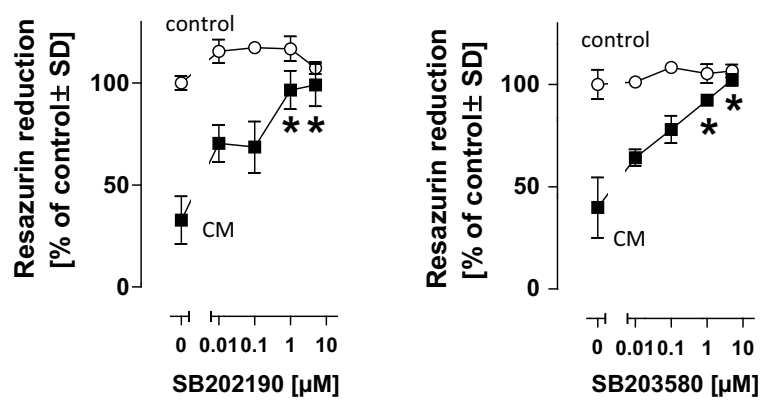

Fig. 8 Protection of neurons by prevention of astrocyte activation. a Experimental schematic representation. IMA monocultures were pre-treated with $\mathbf{b}$ dexamethasone; $t$ test, ${ }^{*} p<0.05$ (dexamethasone untreated vs. treated in the presence of $\mathrm{CM}$ ) or $\mathbf{c}$ two different p38 inhibitors, SB202190 or SB203580, $* p<0.05$ (SB202190 or SB203580 untreated vs. treated in the presence of CM) for $30 \mathrm{~min}$ before stimulation with $\mathrm{CM}$. After 6 days, conditioned medium was collected, then diluted $(3+1)$ with fresh medium, and transferred to d6 LUHMES monocultures for 3 additional days. Afterwards, the neuronal viability was measured by the resazurin reduction assay. Data are expressed as mean \pm SD of three experiments. Statistics were performed using one-way ANOVA followed by a Dunnett's multiple comparison post hoc test

also can lead to active killing of human neurons by soluble factors. The effect described here in detail for a murine astrocytic cell line was also reproduced by human primary astrocytes. As neurotoxic factors were transferrable by stored and frozen supernatants, and as the toxicity required considerable time (days) to develop, we conclude that the mediators responsible for the neurodegeneration observed in our model system are different from reactive oxygen/ nitrogen species, elevated extracellular glutamate levels, or excitotoxins described in other models (Fig. S1). Therefore, the astroglia-dependent neurotoxicity, occurring in the co-culture model established here, differs also significantly from several forms of microglia-dependent neurotoxicity observed in vitro and in vivo (Block et al. 2007; Brown and Neher 2010).

When we explored the suitability of our system to investigate potentially neuroprotective agents, we identified seven types of intervention that can be grouped according to the target cell involved. The first set of compounds acted on astrocytes. For instance, the inhibition of p38 MAP kinases was not beneficial, when restricted to neurons, but it prevented formation of the neurotoxic activity by astrocytes. The same was observed for dexamethasone, a glucocorticoid used in clinical neurology for the treatment of brain inflammation. Five other types of drugs blocked cell death and neurite degeneration directly on the level of neurons. Thus, the 'astrocyte inflammation-LUHMES model' expands the available options (Fig. S1) for efficacy and target finding assays in drug discovery.

Research on neuronal dysfunctions in neurodegenerative diseases has revealed many important cell autonomous mechanisms, such as neuronal programmed cell death and disturbances of proteostasis, often linked to disturbed calcium regulation, oxidative stress, or amyloid formation. More recent research has shown that also non-neuronal cells may play a role in neurodegeneration. For instance, genetic or non-genetic alterations in astroglial cells may adversely affect the survival of neurons in models of human diseases related to the RETT syndrome, Huntington's disease, Parkinson's disease, multiple sclerosis, or amyotrophic lateral sclerosis (Gallardo et al. 2014; Kohutnicka et al. 1998; Lukovic et al. 2015; Mayo et al. 2014; Valenza et al. 2015; Williams et al. 2014).

Studies on the role of microglia toxicity to neurons have shown that in vitro models and co-cultures are valuable for identification of potential mechanisms, although the confirmation of their relevance in vivo is still under debate, and may be limited to more chronic models (Biber et al. 2014). Studies in this field have shown that the use of cocultures provides new information due to the sometimes unpredictable reciprocal interactions of the cells. It is, for instance, known from the interactions of immune cells that inflammatory reactions may be dramatically boosted in feed-forward loops, and that they can therefore not be predicted from reactions of individual cells (Gantner et al. 1996). Something similar may apply to the cycle of activated astrocytes affecting neurons and stressed neurons further activating astrocytes (Valenza et al. 2015; Volterra and Meldolesi 2005).

The co-culture system described here allowed the observation of three situations. In the ground state, the astrocytes protected neurons from external toxic stimuli. This is an established feature of astrocyte-neuron interaction (Dodla et al. 2010; Gupta et al. 2012; Lukovic et al. 2015), and it involves, for instance, thiol transfer from astrocytes to neurons. Accordingly, block of GSH synthesis in our model also prevented the protective effect of astrocytes (not shown), as described in similar approaches earlier (Chen et al. 2001; Gupta et al. 2012; Lee et al. 2010).

The second situation involves the inflammatory stimulation. Activation of the astrocytes by pro-inflammatory cytokines (TNF- $\alpha$, IL-1 $\beta$ ) is well established (Falsig et al. 
2004a, b, 2006, 2008; Henn et al. 2011; Kohutnicka et al. 1998), and our model recapitulated many of the wellknown features, such as NF-kB translocation, and morphological alterations reminiscent of the one of the migrating activated astrocytes (Buffo et al. 2010). The activation of astrocytes is not fully understood. Therefore, we do not know which of the many early signals affected by dexamethasone is responsible for the long-term consequences concerning neuronal survival. Only specific inhibitors of p38 kinases, out of several other anti-inflammatory drugs tested, were also protective. This agrees well with an earlier finding that only p38 inhibitors affected the endpoint of activation-induced cell death in primary murine astrocytes (Falsig et al. 2004a, b). The activation process and production of the neurocytotoxic supernatant depend also on the initial state of IMA (proliferation; passage number). This may imply that different astrocyte populations or brain regions in in vivo may react differently.

The third situation involved neuronal death triggered by the astrocytes. A major role of soluble factors is suggested by the transferability of the killing activity by supernatant transfer and by defined pharmacological interventions that protected the neurons in this situation.

Concerning the factors released by astrocytes, our preliminary experiments suggest that it is neither a shortlived species (e.g., ROS) nor a type of protein that would lose activity upon boiling. This distinguishes our model from most other model systems based on rodent primary neurons or on neuroblastoma cells (Fig. S1). Further characterization and possibly identification will require extensive experimentation and substantial modifications of the system, so that higher concentrations of the factor are obtained. The latter is a precondition for fractionation experiments. At present, this is not possible, as this would deplete also essential components of the medium required for basic survival of the neurons.

Several candidate factors responsible for astrocyte-mediated toxicity are already known. They comprise cytokines (Buffo et al. 2010; Falsig et al. 2004a; Garwood et al. 2011); lipocalin 2 (Bi et al. 2013), components of the complement system (Bodea et al. 2014; Pekny et al. 2007), or changes due to altered ATPase expression (Gallardo et al. 2014). Besides these mostly proteinaceaous molecules, also some small molecules with cell death-inducing properties have been described. They comprise the glycosphingolipid-lactosylceramide (LacCer) (Mayo et al. 2014), the ganglioside GD3 (Simon et al. 2002), or their basic core component, the pro-apoptotic mediator ceramide (Wang et al. 2012). Possibly, also chondroitin sulfate proteoglycan, which is secreted by astrocytes and impedes axon regeneration (Silver and Miller 2004), may take a toxic role for neurites in cell cultures.
Altogether, the astrocyte inflammation model adds a new, yet unexplored option to test neuroprotective compounds. The pharmacological profile observed here differed from the one observed, e.g., in LUHMES neuron monocultures exposed to $\mathrm{MPP}^{+}$or from LUHMES-astrocyte cultures exposed to MPTP (Efremova et al. 2015). In these two toxicant-driven models, ROCK inhibitors showed a potent neuroprotection, not observed here. Vice versa, the robust protection observed here by high-dose GDNF or of ATB-337 was unique, as it was not observed in the MPTP $\left(\mathrm{MPP}^{+}\right)$model.

In summary, the versatile co-culture model established here will allow future studies (1) on the basic neuroprotective properties of astrocytes; (2) on the transition from the control condition to a slowly developing neurodegenerative state affecting human neurons; (3) pharmacological interventions targeting either astrocytes or neurons; (4) on identification of glia-derived neurodegenerative factors. A better definition of the soluble neurotoxic activity derived from astrocytes, or possibly the identification of a defined factor responsible for it, would greatly help a more direct study of the specific inflammatory signals involved in its production and possibly yield a new biomarker of brain inflammation. Moreover, it will be highly interesting to study mechanisms that might restore, or even boost, the neuroprotective properties of astrocytes, even in a neuroinflammatory environment. A promising approach may be the triggering of the Nrf-2 pathway (Dodla et al. 2010; Gupta et al. 2012) or utilization of the properties of urate in glia-neuron interactions (Cipriani et al. 2012). Moreover, our model might support the quest for specific anti-inflammatory compounds that dampen astrocyte reactions, but not the protective capacity of the peripheral innate immune response.

Acknowledgments This work was supported by the DoerenkampZbinden Foundation, the Land BW, the DFG (RTG1331; KoRS-CB), the BMBF, and University of Konstanz funds.

Author's contribution Liudmila Efremova and Petra Chovancova performed most experiments, analyzed data, and wrote the manuscript; Stefan Schildknecht, Martina Adam, and Simon Gutbier performed experiments and proofread the manuscript; Marcel Leist designed experiments and wrote the manuscript.

\section{References}

Allen NJ, Barres BA (2009) Glia-more than just brain glue. Nature 457:675-677

Avendano BC, Montero TD, Chavez CE, von Bernhardi R, Orellana JA (2015) Prenatal exposure to inflammatory conditions increases Cx43 and Panx1 unopposed channel opening and activation of astrocytes in the offspring effect on neuronal survival. Glia 63(11):2058-2072 
Bal-Price A, Brown GC (2001) Inflammatory neurodegeneration mediated by nitric oxide from activated glia-inhibiting neuronal respiration, causing glutamate release and excitotoxicity. J Neurosci Off J Soc Neurosci 21(17):6480-6491

Bal-Price A, Moneer Z, Brown GC (2002) Nitric oxide induces rapid, calcium-dependent release of vesicular glutamate and ATP from cultured rat astrocytes. Glia 40(3):312-323

Bi F, Huang C, Tong J, Qiu G, Huang B, Wu Q et al (2013) Reactive astrocytes secrete $1 \mathrm{cn} 2$ to promote neuron death. Proc Natl Acad Sci USA 110:4069-4074

Biber K, Owens T, Boddeke E (2014) What is microglia neurotoxicity (not)? Glia 62:841-854

Biesmans S, Acton PD, Cotto C, Langlois X, Ver Donck L, Bouwknecht JA et al (2015) Effect of stress and peripheral immune activation on astrocyte activation in transgenic bioluminescent Gfap-luc mice. Glia 63:1126-1137

Block ML, Zecca L, Hong JS (2007) Microglia-mediated neurotoxicity: uncovering the molecular mechanisms. Nat Rev Neurosci 8:57-69

Bodea LG, Wang Y, Linnartz-Gerlach B, Kopatz J, Sinkkonen L, Musgrove $\mathrm{R}$ et al (2014) Neurodegeneration by activation of the microglial complement-phagosome pathway. J Neurosci 34:8546-8556

Brown GC, Neher JJ (2010) Inflammatory neurodegeneration and mechanisms of microglial killing of neurons. Mol Neurobiol $41: 242-247$

Buffo A, Rolando C, Ceruti S (2010) Astrocytes in the damaged brain: molecular and cellular insights into their reactive response and healing potential. Biochem Pharmacol 79:77-89

Cahoy JD, Emery B, Kaushal A, Foo LC, Zamanian JL, Christopherson KS et al (2008) A transcriptome database for astrocytes, neurons, and oligodendrocytes: a new resource for understanding brain development and function. J Neurosci 28:264-278

Carbone M, Duty S, Rattray M (2012) Riluzole neuroprotection in a Parkinson's disease model involves suppression of reactive astrocytosis but not GLT-1 regulation. BMC Neurosci 13:38

Castillo J, Dávalos A, Alvarez-Sabín J, Pumar JM, Leira R et al (2002) Molecular signatures of brain injury after intracerebral hemorrhage. Neurology 58:624-629

Chen Y, Vartiainen NE, Ying W, Chan PH, Koistinaho J, Swanson RA (2001) Astrocytes protect neurons from nitric oxide toxicity by a glutathione-dependent mechanism. J Neurochem 77:1601-1610

Cipriani S, Desjardins CA, Burdett TC, Xu Y, Xu K, Schwarzschild MA (2012) Protection of dopaminergic cells by urate requires its accumulation in astrocytes. J Neurochem 123:172-181

Dodla MC, Mumaw J, Stice SL (2010) Role of astrocytes, soluble factors, cells adhesion molecules and neurotrophins in functional synapse formation: implications for human embryonic stem cell derived neurons. Curr Stem Cell Res Ther 5:251-260

Efremova L, Schildknecht S, Adam M, Pape R, Gutbier S, Hanf B et al (2015) Prevention of human dopaminergic neurodegeneration in an astrocytes co-culture system allowing endogenous drug metabolism. Br J Pharmacol 172:4119-4132

Falsig J, Latta M, Leist M (2004a) Defined inflammatory states in astrocyte cultures: correlation with susceptibility towards CD95driven apoptosis. J Neurochem 88:181-193

Falsig J, Porzgen P, Lotharius J, Leist M (2004b) Specific modulation of astrocyte inflammation by inhibition of mixed lineage kinases with CEP-1347. J Immunol 173:2762-2770

Falsig J, Porzgen P, Lund S, Schrattenholz A, Leist M (2006) The inflammatory transcriptome of reactive murine astrocytes and implications for their innate immune function. J Neurochem 96:893-907

Falsig J, van Beek J, Hermann C, Leist M (2008) Molecular basis for detection of invading pathogens in the brain. J Neurosci Res $86: 1434-1447$
Forno LS, DeLanney LE, Irwin I, Di Monte D, Langston JW (1992) Astrocytes and Parkinson's disease. Prog Brain Res 94:429-436

Gallardo G, Barowski J, Ravits J, Siddique T, Lingrel JB, Robertson $\mathrm{J}$ et al (2014) An alpha2-Na/K ATPase/alpha-adducin complex in astrocytes triggers non-cell autonomous neurodegeneration. Nat Neurosci 17:1710-1719

Gandelman M, Peluffo H, Beckman JS, Cassina P, Barbeito L (2010) Extracellular ATP and the P2X7 receptor in astrocyte-mediated motor neuron death: implications for amyotrophic lateral sclerosis. J Neuroinflammation 7:33

Gantner F, Leist M, Kusters S, Vogt K, Volk HD, Tiegs G (1996) T cell stimulus-induced crosstalk between lymphocytes and liver macrophages results in augmented cytokine release. Exp Cell Res 229:137-146

Gao X, Chen H, Schwarzschild MA, Ascherio A (2011) Use of ibuprofen and risk of Parkinson disease. Neurology 76:863-869

Garwood CJ, Pooler AM, Atherton J, Hanger DP, Noble W (2011) Astrocytes are important mediators of Abeta-induced neurotoxicity and tau phosphorylation in primary culture. Cell Death Dis 2:e167

Gegg ME, Clark JB (1036) Heales, SJ (2005) Co-culture of neurones with glutathione deficient astrocytes leads to increased neuronal susceptibility to nitric oxide and increased glutamate-cysteine ligase activity. Brain Res 1-2:1-6

Gomez Perdiguero E, Klapproth K, Schulz C, Busch K, Azzoni E, Crozet L et al (2015) Tissue-resident macrophages originate from yolk-sac-derived erythro-myeloid progenitors. Nature 518:547-551

Guizzetti M, Moore NH, Giordano G, Costa LG (2008) Modulation of neuritogenesis by astrocyte muscarinic receptors. J Biol Chem 283:31884-31897

Gupta K, Patani R, Baxter P, Serio A, Story D, Tsujita T et al (2012) Human embryonic stem cell derived astrocytes mediate noncell-autonomous neuroprotection through endogenous and druginduced mechanisms. Cell Death Differ 19:779-787

Hansson O, Castilho RF, Kaminski Schierle GS, Karlsson J, Nicotera P, Leist M et al (2000) Additive effects of caspase inhibitor and lazaroid on the survival of transplanted rat and human embryonic dopamine neurons. Exp Neurol 164:102-111

Hashioka S, McGeer EG, Miyaoka T, Wake R, Horiguchi J, McGeer PL (2015) Interferon-gamma-induced neurotoxicity of human astrocytes. CNS Neurol Disord: Drug Targets 14(2):251-256

Heneka MT, Kummer MP, Latz E (2014) Innate immune activation in neurodegenerative disease. Nat Rev Immunol 14(7):463-477

Heneka MT, Carson MJ, El Khoury J, Landreth GE, Brosseron F, Feinstein DL, Jacobs AH, Wyss-Coray T, Vitorica J, Ransohoff RM, Herrup K, Frautschy SA, Finsen B, Brown GC, Verkhratsky A, Yamanaka K, Koistinaho J, Latz E, Halle A, Petzold GC, Town T, Morgan D, Shinohara ML, Perry VH, Holmes C, Bazan NG, Brooks DJ, Hunot S, Joseph B, Deigendesch N, Garaschuk O, Boddeke E, Dinarello CA, Breitner JC, Cole GM, Golenbock DT, Kummer MP (2015) Neuroinflammation in Alzheimer's disease. Lancet Neurol 14(4):388-405

Henn A, Kirner S, Leist M (2011) TLR2 hypersensitivity of astrocytes as functional consequence of previous inflammatory episodes. J Immunol 186:3237-3247

Hunter RL, Cheng B, Choi DY, Liu M, Liu S, Cass WA et al (2009) Intrastriatal lipopolysaccharide injection induces parkinsonism in C57/B6 mice. J Neurosci Res 87:1913-1921

In'T Veld BA, Ruitenberg A, Hofman A, Launer LJ, van Duijn CM, Stijnen $T$ et al (2001) Nonsteroidal antiinflammatory drugs and the risk of Alzheimer's disease. N Engl J Med 345:1515-1521

Kohutnicka M, Lewandowska E, Kurkowska-Jastrzebska I, Czlonkowski A, Czlonkowska A (1998) Microglial and astrocytic involvement in a murine model of Parkinson's disease induced 
by 1-methyl-4-phenyl-1,2,3,6-tetrahydropyridine (MPTP). Immunopharmacology 39:167-180

Krug AK, Gutbier S, Zhao L, Poltl D, Kullmann C, Ivanova V et al (2014) Transcriptional and metabolic adaptation of human neurons to the mitochondrial toxicant MPP(+). Cell Death Dis 5:e1222

Kuegler PB, Baumann BA, Zimmer B, Keller S, Marx A, Kadereit S et al (2012) GFAP-independent inflammatory competence and trophic functions of astrocytes generated from murine embryonic stem cells. Glia 60:218-228

Kurkowska-Jastrzebska I, Litwin T, Joniec I, Ciesielska A, Przybylkowski A, Czlonkowski A et al (2004) Dexamethasone protects against dopaminergic neurons damage in a mouse model of Parkinson's disease. Int Immunopharmacol 4:1307-1318

Lee M, Cho T, Jantaratnotai N, Wang YT, McGeer E, McGeer PL (2010) Depletion of GSH in glial cells induces neurotoxicity: relevance to aging and degenerative neurological diseases. FASEB J 24(7):2533-2545

Lee M, McGeer E, Kodela R, Kashfi K, McGeer PL (2013a) NOSHaspirin (NBS-1120), a novel nitric oxide and hydrogen sulfide releasing hybrid, attenuates neuroinflammation induced by microglial and astrocytic activation: a new candidate for treatment of neurodegenerative disorders. Glia 61(10):1724-1734

Lee M, McGeer E, McGeer PL (2013b) Neurotoxins released from interferon-gamma-stimulated human astrocytes. Neuroscience 229:164-175

Lindholm P, Voutilainen MH, Lauren J, Peranen J, Leppanen VM, Andressoo JO et al (2007) Novel neurotrophic factor CDNF protects and rescues midbrain dopamine neurons in vivo. Nature 448:73-77

Lioy DT, Garg SK, Monaghan CE, Raber J, Foust KD, Kaspar BK et al (2011) A role for glia in the progression of Rett's syndrome. Nature 475:497-500

Lukovic D, Stojkovic M, Moreno-Manzano V, Jendelova P, Sykova E, Bhattacharya SS et al (2015) Concise review: reactive astrocytes and stem cells in spinal cord injury: good guys or bad guys? Stem Cells 33:1036-1041

Ma D, Jin S, Li E, Doi Y, Parajuli B, Noda M et al (2013) The neurotoxic effect of astrocytes activated with toll-like receptor ligands. J Neuroimmunol 254:10-18

Mander P, Borutaite V, Moncada S, Brown GC (2005) Nitric oxide from inflammatory-activated glia synergizes with hypoxia to induce neuronal death. J Neurosci Res 79(1-2):208-215

Maragakis NJ, Rothstein JD (2006) Mechanisms of disease: astrocytes in neurodegenerative disease. Nat Clin Pract Neurol 2:679-689

Mattson MP, Barger SW, Furukawa K, Bruce AJ, Wyss-Coray T, Mark RJ et al (1997) Cellular signaling roles of TGF beta, TNF alpha and beta APP in brain injury responses and Alzheimer's disease. Brain Res Brain Res Rev 23:47-61

Mayo L, Trauger SA, Blain M, Nadeau M, Patel B, Alvarez JI et al (2014) Regulation of astrocyte activation by glycolipids drives chronic CNS inflammation. Nat Med 20:1147-1156

Medeiros R, LaFerla FM (2013) Astrocytes: conductors of the Alzheimer disease neuroinflammatory symphony. Exp Neurol 239:133-138

Nagai M, Re DB, Nagata T, Chalazonitis A, Jessell TM, Wichterle H, Przedborski S (2007) Astrocytes expressing ALS-linked mutated SOD1 release factors selectively toxic to motor neurons. Nat Neurosci 10(5):615-622

Orre M, Kamphuis W, Osborn LM, Jansen AH, Kooijman L, Bossers $\mathrm{K}$ et al (2014) Isolation of glia from Alzheimer's mice reveals inflammation and dysfunction. Neurobiol Aging 35:2746-2760

Pekny M, Wilhelmsson U, Bogestal YR, Pekna M (2007) The role of astrocytes and complement system in neural plasticity. Int Rev Neurobiol 82:95-111
Pizzurro DM, Dao K, Costa LG (2014) Astrocytes protect against diazinon- and diazoxon-induced inhibition of neurite outgrowth by regulating neuronal glutathione. Toxicology 318:59-68

Puschmann TB, Zanden C, De Pablo Y, Kirchhoff F, Pekna M, Liu J et al (2013) Bioactive 3D cell culture system minimizes cellular stress and maintains the in vivo-like morphological complexity of astroglial cells. Glia 61:432-440

Rees K, Stowe R, Patel S, Ives N, Breen K, Clarke CE et al (2011) Non-steroidal anti-inflammatory drugs as disease-modifying agents for Parkinson's disease: evidence from observational studies. Cochrane Database Syst Rev. doi:10.1002/14651858. CD008454

Robel S, Berninger B, Gotz M (2011) The stem cell potential of glia: lessons from reactive gliosis. Nat Rev Neurosci 12:88-104

Ruitenberg A, Kalmijn S, de Ridder MA, Redekop WK, van Harskamp F, Hofman A et al (2001) Prognosis of Alzheimer's disease: the Rotterdam Study. Neuroepidemiology 20:188-195

Sandstrom von Tobel J, Zoia D, Althaus J, Antinori P, Mermoud J, Pak HS et al (2014) Immediate and delayed effects of subchronic Paraquat exposure during an early differentiation stage in 3D-rat brain cell cultures. Toxicol Lett 230:188-197

Schildknecht S, Kirner S, Henn A, Gasparic K, Pape R, Efremova L et al (2012) Characterization of mouse cell line IMA 2.1 as a potential model system to study astrocyte functions. Altex Altern Anim Exp 29:261-274

Scholz D, Poltl D, Genewsky A, Weng M, Waldmann T, Schildknecht $S$ et al (2011) Rapid, complete and large-scale generation of post-mitotic neurons from the human LUHMES cell line. J Neurochem 119:957-971

Shih AY, Johnson DA, Wong G, Kraft AD, Jiang L, Erb H et al (2003) Coordinate regulation of glutathione biosynthesis and release by Nrf2-expressing glia potently protects neurons from oxidative stress. J Neurosci 23:3394-3406

Silver J, Miller JH (2004) Regeneration beyond the glial scar. Nat Rev Neurosci 5:146-156

Simon BM, Malisan F, Testi R, Nicotera P, Leist M (2002) Disialoganglioside GD3 is released by microglia and induces oligodendrocyte apoptosis. Cell Death Differ 9:758-767

Sofroniew MV, Vinters HV (2010) Astrocytes: biology and pathology. Acta Neuropathol 119:7-35

Valenza M, Marullo M, Di Paolo E, Cesana E, Zuccato C, Biella G et al (2015) Disruption of astrocyte-neuron cholesterol cross talk affects neuronal function in Huntington's disease. Cell Death Differ 22:690-702

Volterra A, Meldolesi J (2005) Astrocytes, from brain glue to communication elements: the revolution continues. Nat Rev Neurosci 6:626-640

Walker DG, Kim SU, McGeer PL (1998) Expression of complement C4 and C9 genes by human astrocytes. Brain Res 809(1):31-38

Wang G, Dinkins M, He Q, Zhu G, Poirier C, Campbell A et al (2012) Astrocytes secrete exosomes enriched with proapoptotic ceramide and prostate apoptosis response 4 (PAR-4): potential mechanism of apoptosis induction in Alzheimer disease (AD). J Biol Chem 287:21384-21395

Ward RJ, Colivicchi MA, Allen R, Schol F, Lallemand F, de Witte P, Ballini $C$ et al (2009) Neuro-inflammation induced in the hippocampus of 'binge drinking' rats may be mediated by elevated extracellular glutamate content. J Neurochem 111:1119-1128

Williams EC, Zhong X, Mohamed A, Li R, Liu Y, Dong Q et al (2014) Mutant astrocytes differentiated from Rett syndrome patientsspecific iPSCs have adverse effects on wild-type neurons. Hum Mol Genet 23:2968-2980 